\title{
?17 tinbergen
}

TI 2021-063/VII

Tinbergen Institute Discussion Paper

\section{Corporate Social Responsibility by Joint Agreement}

Revision October 2021

Maarten Pieter Schinkel ${ }^{1}$

Leonard Treuren ${ }^{1}$

${ }^{1}$ University of Amsterdam and Tinbergen Institute 
Tinbergen Institute is the graduate school and research institute in economics of Erasmus University Rotterdam, the University of Amsterdam and Vrije Universiteit Amsterdam.

Contact: discussionpapers@tinbergen.nl

More TI discussion papers can be downloaded at https://www.tinbergen.nl

Tinbergen Institute has two locations:

Tinbergen Institute Amsterdam

Gustav Mahlerplein 117

1082 MS Amsterdam

The Netherlands

Tel.: +31(0)205984580

Tinbergen Institute Rotterdam

Burg. Oudlaan 50

3062 PA Rotterdam

The Netherlands

Tel.: +31(0)10408 8900 


\title{
Corporate Social Responsibility by Joint Agreement*
}

\author{
Maarten Pieter Schinkel ${ }^{\dagger}$ and Leonard Treuren ${ }^{\ddagger}$
}

October 2021

\begin{abstract}
Industry-wide voluntary agreements are touted as a means for corporations to take more corporate social responsibility (CSR). We study what type of joint CSR agreement induces competitors to increase CSR efforts in a model of oligopolistic competition with differentiated products. Consumers have a willingness to pay for more responsibly manufactured products. Firms are driven by profit, and are also possibly intrinsically motivated, to invest in CSR efforts. We find that cooperative agreements directly on the level of CSR reduce CSR efforts compared to competition. Such agreements throttle both for-profit and intrinsic motivation for CSR. CSR efforts only increase if agreements are permitted solely on output. Such production agreements, however, reduce total welfare in the market and raise antitrust concerns. Taking externalities into account may help justify a production agreement under a broader welfare standard, but not agreements on CSR directly. Moreover, simply requiring a higher CSR level by regulation while preserving competition always gives higher within-market welfare.
\end{abstract}

Keywords: CSR, collaboration, voluntary agreement, cartel, antitrust, externalities, regulation

JEL Codes: K21, L13, L40, Q01

*We thank Maurits Dolmans, Robert Dur, Timo Klein, Jeanine Miklós-Thal, Sander Onderstal, Thomas Ross, Yossi Spiegel, Jan Tuinstra, and Jeroen van de Ven for helpful discussions and suggestions. We also appreciate comments made by participants of various conferences and seminars in which we presented preliminary and partial findings from the research here reported on in full, including the 2018 IIOC in Indianapolis, the 2018 EARIE conference in Athens, 2019 BECCLE, 2019 SMYE, 2021 CLEEN, OECD conferences on Sustainability and Competition in 2020 and 2021, and the European Commission's conference, 4th February 2021, on Competition Policy Contributing to the Green Deal. Opinions and errors remain ours.

$\dagger$ University of Amsterdam and Tinbergen Institute; .P.Schinkel@uva.nl

$\ddagger$ University of Amsterdam and Tinbergen Institute; L.M.Treuren@uva.nI 


\section{Introduction}

There is a growing realization that certain social objectives, such as diverting climate change, assuring fair trade that respects human rights, and promoting public health, urgently require drastic measures that governments often fail to take. With this realization have come appeals that corporations should take more social responsibility and serve wider stakeholder interests beyond mere shareholder value. A prominent recent call is that agreements amongst competitors are required to induce impactful corporate social responsibility (CSR) efforts. Nidumolu et al. (2014) claim that business collaboration is imperative to advancing sustainability. Kotchen and Segerson (2019) advocate voluntary collective agreements to solve commons problems in natural resource sectors such as forestry and fishery. Henderson (2020) calls for "industry-wide cooperation", and Polman and Winston (2021) tout "pre-competitive collaboration" to stop environmental degradation and economic inequality.

Practice is going ahead with joint CSR agreements. The Business Roundtable united close to two hundred companies to "share a fundamental commitment to all of our stakeholders", including the environment. ${ }^{1}$ Imagine and the Consumer Goods Forum are industry-wide collaboration fora to tackle climate change and global inequality. ${ }^{2}$ Chocolate producers want jointly to improve the livelihood of cocoa farmers under the tutelage of the Fair Trade Advocacy Office, garment labels join forces to ban plastics in the Fashion Pact, and truck manufacturers pledged to phase out diesel engines under ACEA umbrella. ${ }^{3}$ Earlier cases of collaboration to induce CSR efforts are given in Lyon and Maxwell (2004) and Peloza and Falkenberg (2009).

In this paper, we study what type(s) of joint CSR agreements amongst competitors advance CSR activities. The public interests to which CSR aims to contribute can require central coordination. Where governments fail to provide such coordination - for lack of legal instruments, information, political power, or otherwise - private coordination may be a solution. On the other hand, growing consumer appreciation and willingness to pay for more responsibly produced goods elevate CSR as a dimension of product and corporate image differentiation. Companies increasingly recognize that consumers turn away from products perceived as unjust, unfair, or unsustainably manufactured. This allows firms to monetize a comparative advantage in CSR on their rivals. ${ }^{4}$ Consumers wanting to buy from firms that are serious about their CSR is a fast-growing force that compels corporations to take more responsibility for environmental and social objectives. ${ }^{5}$

\footnotetext{
${ }^{1}$ See businessroundtable.org.

${ }^{2}$ See imagine.one and theconsumergoodsforum.com.

${ }^{3}$ See fairtrade-advocacy.org., thefashionpact.org and acea.be., respectively.

${ }^{4}$ Bansal and Roth (2000) and Porter and Kramer (2006) identified the strategic CSR business model, on which a large literature has developed since. See Kitzmueller and Shimshack (2012) for an overview.

${ }^{5}$ Servaes and Tamayo (2013) stress the role of customer awareness, and in particular reputation, as a responsible company. Delmas and Colgan (2018) point out that while consumers' willingness to pay for CSR out of pure altruism may be small, it is boosted by perceived features such as improved
} 
When CSR allows firms to differentiate themselves, then joint agreements on CSR efforts amongst firms in the same industry eliminate a dimension of competition. For this reason, cooperative CSR initiatives raise antitrust concerns. Competition law scholars have pointed at possibilities to exempt agreements that promote CSR benefits from cartel law. ${ }^{6}$ Under the U.S. statutes on competition, the pursuit of wider public interests has little traction as an antitrust defense. Indeed, car manufacturers that agreed with the State of California to increase standards above the Federal standards for tailpipe emissions were promptly investigated for collusion. ${ }^{7}$ In Europe, there may be more legal leeway, but there are few precedents to date beyond washing machines and powders. ${ }^{8}$ Instead, the European Commission fined car manufacturers for colluding to retard cleaner emissions technology. ${ }^{9}$ Proponents of deploying collaboration between competitors in the fight against climate change are calling for more guidance on when sustainability agreements may be permitted. ${ }^{10}$

The central premise of advocates of allowing joint agreements to promote CSR is that corporations will take more social responsibility when they face less competition. This resonates with a literature that attributes erosion of social responsibility to market competition. Shleifer (2004) gives some examples of ethical behavior undermined by competitive pressures and the need to cut costs. Falk and Szech (2013) and Bartling et al. (2015) find experimental evidence suggesting that intrinsic CSR behavior may be eroded in market settings - even though the number of competing subjects has no significant effect on that erosion. Yet theoretical and empirical studies on the relationship between market competition and CSR efforts, reviewed in the next section, suggest the opposite predominantly.

We study three different types of joint CSR agreements in a model of oligopolistic competition with differentiated goods, including by the CSR efforts of their manufacturer. Consumers prefer to buy from companies committed to CSR, and have a higher willingness to pay for their products. Reasons why firms may act responsibly range from purely profit motivation to purely intrinsic motivation. ${ }^{11}$ We consider varying combinations. Firms base their business decisions, including their CSR efforts, first and foremost on profit. A pronounced CSR profile allows a company to attract more

performance, health attributes, savings, status, and peer pressure.

${ }^{6}$ See Scott (2016) for cartel exemption possibilities under U.S. antitrust law, and Holmes (2020) under European competition law.

${ }^{7}$ See Hovenkamp (2019).

${ }^{8}$ In CECED (1999), the European Commission allowed washing machine producers to agree to take their least energy-efficient models collectively off the market. However, the avoided emissions were not pivotal to the decision. Instead, the Commission concluded that typical consumers would be compensated for the increased purchase costs of a more energy-efficient washing machine by savings on their electricity bills. See CECED (1999), recital 56 and Ahmed and Segerson (2011). Some years later, in the complementary market for household laundry detergents, an accredited industry initiative to promote more sustainable washing powders became a cover for price collusion in Consumer Detergents (2011).

${ }^{9}$ See Car Emissions (2021).

${ }^{10}$ See Holmes et al. (2021).

${ }^{11}$ See Bénabou and Tirole (2010). 
customers and charge higher prices.

In addition to these immediate for-profit objectives for strategic CSR, our model also allows companies with intrinsic reasons to invest in CSR. Forward-looking corporations may believe that contributing to society builds goodwill and a reputation that will pay off in the long run, even when immediate demand is small. For example, former Unilever CEO Paul Polman teaches that a company can only be successful when its long-run planning is "close to society" by taking its externalities into account. ${ }^{12}$ Large investment funds, such as Blackrock and Vanguard, seem to follow the call by making public commitments to reduce emissions. ${ }^{13}$ A direct "intrinsic" motivation for CSR efforts in our model captures a variety of reasons for companies to put weight on social issues beyond their explicit profit motive.

CSR efforts have implications for a company's costs. Many of the motivating calls for collaborative CSR concern the need for firms to make a transition by implementing known alternative production methods. For example, installing CO2 filters, switching from plastics to biodegradable packaging materials, banning child labor from the supply chain, or improving the living conditions of farm animals. Such transitions come at a fixed cost that increases with the level of CSR efforts. The cost of attracting capital for such investments can be lower for firms with a stronger CSR profile, with fixed and variable cost implications. Firms with better CSR scores are found to have better access to capital and cheaper equity financing, due to a growing reluctance of consumers and investors to fund gray production. ${ }^{14}$ CSR efforts may also affect the marginal costs of production. Typically, concrete steps such as paying fairer wages and applying biological pesticides will increase per unit production costs. CSR efforts can also decrease marginal costs of production. Sustainable sourcing can increase yields and be awarded government subsidies, for example. Also, employees are found willing to accept lower wages working for socially driven companies. ${ }^{15}$

The transition to higher CSR levels that motivate this paper are not about research and development of new technologies. ${ }^{16}$ It is important to note the difference with implementation, since R\&D investments are often characterized by positive spillover effects, by which one firm benefits from another firm's innovation. If such spillovers are substantial, they discourage unilateral investments, and research joint-ventures (RJVs) can increase R\&D efforts above competitive levels. ${ }^{17}$ This is one reason why broad exemption clauses exist for RJVs that also extend to cooperative research into

\footnotetext{
${ }^{12}$ See Polman and Winston (2021). Chatterji and Toffel (2019) refer to this as "CEO activism".

${ }^{13}$ See Azar et al. (2021) and Kerber (2021).

${ }^{14}$ See Sharfman and Fernando (2008), El Ghoul et al. (2011), and Cheng et al. (2014).

${ }^{15}$ See Ignatius (2012) on increased yield, and de Bettignies et al. (2020) on green human resource management. Flammer (2015a) reports higher labor productivity.

${ }^{16}$ Lenox and Chatterji (2018) focus on the role of business and competitive markets, in collaboration with different levels of government, as a catalyst for green innovation and change. Gans (2012) shows that the right interaction with policy is crucial.

${ }^{17}$ Seminal contributions are d'Aspremont and Jacquemin (1988) and Kamien et al. (1992). Firms first coordinate investments in cost-reducing $R \& D$ and subsequently compete in the output market. This is in line with our analysis of CSR agreements.
} 
more socially responsible and environmentally friendly production methods. ${ }^{18}$ With limited spillovers, however, competition is found to be the more potent driver of $R \& D$ investments. We analyze agreements where spillovers are absent and only briefly discuss them again in the concluding remarks.

In our model, each firm first commits to a CSR level and subsequently decides how much to produce. This is in line with the notion of 'pre-competitive' agreements. We analyze the effects of joint agreements on CSR efforts, production, and prices when firms coordinate their CSR efforts, their production volumes, or about both. A robust finding is that joint agreements that involve CSR levels directly - either agreements on CSR efforts alone or together with coordinated production - reduce CSR efforts compared to competition. This is true for any positive willingness to pay for CSR, no matter how little. The reason is that CSR coordination eliminates CSR as a dimension of competition, which allows firms to profit from lower CSR investment costs. These findings hold irrespective of the strength of companies' intrinsic motivation for CSR. Intrinsic motivation magnifies our polar results. CSR coordination reduces the additional CSR due to intrinsic motivation. If CSR is to be increased by collaboration, only permitting coordination of output volumes (or prices) delivers. It increases the total rents from CSR investments while maintaining competition for a larger share of those rents by each firm investing more in CSR.

Output (and price) agreements, however, are particularly problematic under the antitrust laws. Moreover, whenever firms have an incentive to form such agreements, we find that within-market welfare is reduced. A current requirement under European competition law for obtaining a cartel exemption for an anticompetitive horizontal agreement is full compensation of the consumers of the products concerned. Our findings imply that this is not possible, as no joint agreement exists that simultaneously increases CSR levels, consumer welfare ánd profit over the competitive situation. Hence, the consumer compensation requirement must be relaxed if CSR is to be promoted by joint (output or price) agreements.

One possibility is to also take benefits outside the relevant market, such as externalities, into account. ${ }^{19}$ When production causes negative externalities to non-consumers, and CSR efforts reduce those externalities, another reason arises to favor production agreements over agreements on CSR directly. Production agreements decrease negative productions externalities, while CSR agreements, which result in lower output and less CSR, do not. Allowing consumers to be harmed while valuing non-consumer benefits is not standard practice in competition policy, however. Such out-of-market benefits are also rather complex to assess. We show that government regulation is likely the better alternative. Welfare is always higher when the government simply mandates the CSR efforts that a production agreement would provide.

This paper contributes to the debate on the role of corporate collaboration to stim-

\footnotetext{
${ }^{18}$ When spillovers are substantial, so that firms have an incentive to free-ride, the design of stable voluntary agreements is not obvious. See Brau and Carraro (2011).

${ }^{19}$ The Dutch competition authority proposes this in Authority for Consumers and Markets (2021). See Schinkel and Treuren (2021) for a critical review.
} 
ulate CSR. We add to the broader literature on strategic CSR by studying the role of competition in four possible scenarios in a semi-collusion model. Any number, or subset, of firms in a relevant market either compete or cooperate on setting quantities (or prices) and/or their CSR efforts. CSR investments can affect the fixed and variable cost of production, and consumers' willingness to pay for more responsibly manufactured products is variable and can be small. Inspired by CEO activism, firms may be motivated not solely by short-term profit maximization, but also intrinsically to invest in CSR. We show that collaborative CSR agreements amongst competitors never increase CSR levels, but production (or price) agreements do.

We relate our formal findings to the four principal legal requirements for exempting joint agreements from antitrust. In addition, by considering out-of-market efficiencies, the novel point is made that while cooperation-induced output restrictions can mitigate negative production externalities, cooperation-induced CSR decreases will increase them. Our findings warn activist CEOs, corporate lawyers, and others who propose collaborative CSR with the best intentions. Those advocates better advise that companies remain in competition on strategic CSR. An important policy implication is that antitrust authorities should be dismissive of applications for a cartel law exemption of agreements claiming to promote CRS.

The remainder of the paper is organized as follows. In the next section, we briefly discuss related literature and identify how this paper contributes. In Section 3, the model of competition in CSR efforts and quantities is introduced. In Section 4, we analyze what level of CSR results under different types of joint agreements. In Section 5 , we study welfare effects. Section 6 discusses how production agreements that advance CSR efforts may qualify for an antitrust exemption, despite harming consumers, by taking wider, out-of-market-efficiencies into account. Section 7 concludes. Proofs are given in Appendix A. Robustness analyses in case of price-setting instead of quantitysetting, an alternative demand system, and partial CSR agreements that do not involve all competitors are discussed in Appendices B to D.

\section{Related literature}

The debate on whether companies should pursue CSR objectives goes back at least to Friedman's 1970 dictum that firms strive for nothing but profits. In the strategic CSR literature, doing well and doing good are aligned when consumers appreciate CSR efforts so that firms can profit by elevating their CSR profile. Early contribution on strategic CSR as a for-profit product differentiation strategy are Baron (2001) and McWilliams and Siegel (2001). Baron (2007) studies social entrepreneurship out of 'warm-glow' preferences. Bénabou and Tirole (2010) analyze the range of motivations for responsible business behavior between pure profit and pure intrinsic motivation. In surveys, executives indeed report both financial and intrinsic motives for engaging in CSR. ${ }^{20}$ Hart and Zingales $(2017 \mathrm{a}, \mathrm{b})$ point out that firms are right to pursue CSR

\footnotetext{
${ }^{20}$ See Graafland and Mazereeuw-Van der Duijn Schouten (2012)
} 
objectives that contribute negatively to monetary profit when their shareholders are prosocial.

Empirical studies on the relationship between CSR efforts and market competition predominantly find a positive relationship between the two. Delmas and MontesSancho (2010) critically assess a voluntary agreement in the U.S. on climate. Du et al. (2011) identify CSR as a challenger's competitive weapon against a market leader. Fernández-Kranz and Santaló (2010) and Flammer (2015b) establish with variations in import duties and market concentration that stronger competition increases CSR efforts at the firm level. Simon and Prince (2016) find that a reduction in industrial concentration in the U.S. is associated with lower toxic releases at the factory level. Aghion et al. (2020) report that firms more frequently engage in green innovation if consumers prefer sustainability, and increasingly so in more competitive markets. Ding et al. (2020) directly link antitrust policy to sustainability by showing that stricter competition law regimes are associated with higher CSR. This link is stronger in countries with higher scores on a social norms index that weighs several factors, including consumers' attitudes towards the environment and human rights.

The theoretical literature does not suggest that competition reduces CSR either. Schinkel and Spiegel (2017) show that when consumers have a willingness to pay for more sustainable products, which they perceive as products of higher quality, firms have stronger incentives to promote sustainability in competition than when they can make sustainability agreements. Calveras and Ganuza (2016) study imperfectly observable CSR in a model where firms first decide between clean or dirty technology and subsequently compete in the output market. When firms are in Cournot competition, as opposed to Bertrand competition, a higher degree of CSR observability is required to sustain a given level of CSR. ${ }^{21}$ Dewatripont and Tirole (2020) analyze various market models assuming that for-profit firms internalize (part of) their effects on social welfare. They conclude that whether competition is green or grey depends on the effect of "cutting ethical corners" on demand. When an unconstrained market mechanism determines prices, the intensity of competition does not affect ethical behavior. ${ }^{22}$

Numerous studies support the assumption that consumers are willing to pay more for more responsibly produced goods and services. Casadesus-Masanell et al. (2009) report that people pay more for T-shirts made with organic cotton. In a survey of the literature, Kitzmueller and Shimshack (2012) conclude that willingness to pay

\footnotetext{
${ }^{21}$ Calveras and Ganuza (2018) distinguish between observable external CSR and internal productivity-enhancing CSR and find that both forms help firms differentiate their products by enhancing product quality.

${ }^{22}$ A related literature models CSR as public good provision by private firms, see Kotchen (2006) and Besley and Ghatak (2007). Bagnoli and Watts (2003) find that competition for socially responsible consumers results in private provision of public goods, but at a rate that varies inversely with competition in the private goods market. Gans and Groves (2012) model carbon offsetting as a private public good contribution to find that offsets generally decrease net emissions in competitive markets, but may not when "dirty" producers have market power. Schinkel and Tóth (2019) study a setting where cartels are allowed if consumers are compensated by public good provision. Cartels provide minimal public goods for maximal private overcharges.
} 
positively depends on the degree of CSR a firm engages in, in general. Flammer (2015a) finds sales growth after companies adopt CSR proposals by shareholders. Delmas and Colgan (2018) give many examples of this, in particular with eco-labels. FernándezKranz and Santaló (2010) and Flammer (2015b) interpret their findings that CSR increases with more product market competition as consistent with CSR being strategic since lower profit in competition leaves less scope for intrinsic CSR investments.

Our model extends the duopoly case in Schinkel and Spiegel (2017) to an $n$-firm analysis, with varying consumer willingness to buy from firms that invest more in CSR and firm-side intrinsic motivation for CSR efforts. We also allow for production to generate negative externalities, and consider partial cooperation involving $m$-out-of- $n$ competitors $(m<n)$. Our analysis relates to the semi-collusion literature where firms cooperate in the final goods market but compete in investments. Fershtman and Gandal (1994) and Brod and Shivakumar (1999) analyze the effects of cost-reducing R\&D in duopoly and find that cooperation in the output market paired with competition in the investment stage increase R\&D but not necessarily profit. In more complex extended models, including to $n$-firms, Matsui (1989) studies investments in capacity, Fershtman and Pakes (2000) in product quality, and Symeonidis (2000) in advertising.

\section{A model of strategic CSR investments}

Consider a market in which $n$ firms, labeled $i=1, \ldots, n$, each sell a product that is differentiated, including by the firm's standard of corporate social responsibility (CSR) $v_{i} \geq 0$. An increase in $v_{i}$ can represent, for example, that firm $i$ 's product is manufactured using fewer natural resources, lower emissions production technologies, or a higher standard of care for workers and farm animals in the supply chain. The preferences of a representative consumer over these products, consumed in quantities $\mathbf{q}=q_{1}, \ldots, q_{n}$, are described by the utility function

$$
U(\mathbf{q}, \mathbf{v}, m)=\sum_{i=1}^{n}\left(\alpha+v_{i}\right) q_{i}-\frac{1}{2}\left(\sum_{i=1}^{n} q_{i}^{2}+2 \gamma \sum_{i=1}^{n} \sum_{i>j} q_{i} q_{j}\right)+m
$$

in which $\mathbf{v}=v_{1}, \ldots, v_{n}$ are the firms' CSR levels, $\alpha>0$ is a utility parameter, $\gamma \in$ $(0,1)$ measures the degree of symmetric horizontal product differentiation on other dimensions than CSR, and $m \geq 0$ is expenditure on any other goods. ${ }^{23}$

These preferences yield the following demand system from maximizing $U(\mathbf{q}, \mathbf{v}, m)$ subject to the budget constraint $\sum_{i=1}^{n} p_{i} q_{i}+m \leq I$, where $p_{i}$ is the price of good $i$ and $I$ is representative income

$$
p_{i}\left(\mathbf{q}, v_{i}\right)=\alpha+v_{i}-q_{i}-\gamma \sum_{i \neq j}^{n} q_{j}, \quad i=1, \ldots, n .
$$

\footnotetext{
${ }^{23}$ See Choné and Linnemer (2020) for a recent overview of this widely used preference structure, originally proposed in Shubik and Levitan (1980).
} 
Market demand captures that consumers are willing to pay more for products of firms that invest in higher CSR levels by $v_{i}$ increasing the intercepts. Higher values of $\gamma$ reflect that consumers consider the products to be closer substitutes.

For companies, investing in the transition to a higher level of CSR can be a profitable strategy. Let $\frac{t v_{i}^{2}}{2}$ be firm $i$ 's fixed cost of CSR effort $v_{i}(t \geq 1)$. Regular marginal cost of production are $c$ for all producers. Firm $i$ 's profit then is given by

$$
\pi_{i}\left(\mathbf{q}, v_{i}\right)=\left(\alpha+v_{i}-q_{i}-\gamma \sum_{i \neq j}^{n} q_{j}-c\right) q_{i}-\frac{t v_{i}^{2}}{2},
$$

Note that CSR effort $v_{i}$ can be interpreted as the net effect of willingness to pay for CSR and CSR-induced marginal cost changes on firm $i$ 's price-cost margin $p_{i}-c$. Section 4.2 extends the model to varying willingness to pay for CSR and allows CSR efforts to affect the marginal cost of production.

Firms are for-profit organizations, if only under the pressure of shareholders and investors. They determine their CSR and production levels strategically by maximizing (3). While this is a reasonable baseline assumption, in the domain of socially responsible behavior, firms may also be motivated by other objectives, ranging from a leader's genuine intrinsic willingness to do good to reputational gains not directly reflected in willingness to pay for CSR. In Section 4.3, we study the effects of additional intrinsic motivation for CSR by adding a firm's CSR efforts into its objective function.

The interaction between the $n$ firms involves two stages. In Stage 1, firms simultaneously choose their CSR efforts, which are assumed to be fully observable by consumers and firms. In Stage 2, given their CSR levels $\mathbf{v}$, firms simultaneously decide how much to produce. Note that our sequential setup implies that all firms have committed to their CSR efforts by the time they decide on production (or prices, for that matter). In our motivating examples, strategic company commitment to transit into more sustainable sourcing and manufacturing precedes production volume and sales decisions. A company's CSR investments - such as in cleaner technology or better labor conditions - are costly to reverse and have strategic commitment value. ${ }^{24}$

As all firms are identical, we focus on symmetric pure strategy solutions. In normal competition, each firm $i$ selects both strategic variables $v_{i}$ and $q_{i}$ independently, taking its rivals' decisions as given. This non-cooperative benchmark is denoted by superscript $*$, its unique Nash-equilibrium by $\left(v^{*}, q^{*}\right)$. Firms compete on CSR in the sense that a firm makes itself more attractive to consumers by increasing its CSR efforts, allowing it to steal customers from its competitors. This business-stealing effect induces companies to invest more in CSR. We note that when competition is more intense (for high values $\gamma$ and $n$ ), this can be such a strong force that the firms are whipped up to invest more in CSR than the social optimum that maximizes within-market welfare. Since the

\footnotetext{
${ }^{24}$ In Appendix B, we show that our results carry through if firms select prices in Stage 2 instead of quantities. Whether the Stage 2 agreement is about output or price, in either case, the drive to steal customers by trying to set a higher CSR level becomes stronger when the margin on these customers is larger.
} 
starting point of the initiatives to allow collaborations is that CSR efforts are too low in competition and need stimulation, we are most interested in markets in which higher CSR levels increase total within-market welfare. Proposition 7 in Section 5 specifies general conditions under which this is the case. Nonetheless, we derive all results for all parameter values.

\section{Joint agreements to promote CSR}

To study whether and how allowing companies to make voluntary joint agreements can increase their CSR efforts, we compare CSR levels and output under three types of agreements to the benchmark where no agreements are allowed. First, in a 'CSR agreement' (csr) the firms cooperatively decide on the CSR efforts they each take and subsequently compete on quantities (or prices). This type of agreement is proposed in practice to stimulate CSR, as set out in Section 1. For example, in a carbon cost internalization agreement, producers collectively decide how much each party commits to costing in its emissions value and subsequently are free to decide on their output and prices. The symmetric solution is indicated by $\left(v^{c s r}, q^{c s r}\right)$.

Second, in a 'production agreement' $(p)$, firms coordinate their output volumes while still independently deciding on their CSR efforts. This is the opposite of a CSR agreement and essentially classic cartel behavior. Note, however, that since the firms also compete in CSR efforts, this type of agreement does not fully eliminate competition. To the best of our knowledge, none of the advocates of using joint agreements to stimulate higher CSR efforts has so far advocated sole output coordination. The symmetric solution is indicated by $\left(v^{p}, q^{p}\right)$.

Third, in a 'full agreement' $(f)$, the firms decide cooperatively on their CSR levels and output, thereby fully eliminating competition. While not currently proposed, full agreements may result in practice because allowing firms to coordinate one dimension of competition may give them a forum for discussion that they can abuse to agree on the other dimensions as well. For a competition authority, it will be particularly difficult to monitor and assure that the firms it allows to exchange commercially sensitive information to coordinate their CSR efforts do not misuse that permission to coordinate output (or prices) as well secretly. Well-intended cooperation can slide to hardcore collusion. ${ }^{25}$ The symmetric solution is indicated by $\left(v^{f}, q^{f}\right)$.

In the main text, we study market-wide agreements in which all competitors participate. Exempted from cartel law, these agreements can be contracted and made legally binding before a court. The classic internal and external stability problems that play in illegal market coordination can, therefore, be ignored. Even though their anticom-

\footnotetext{
${ }^{25}$ Duso et al. (2014) find that cartel infringement follows in markets that were previously allowed to form RJVs. Consumer Detergents (2011) is a case in point. Car Emissions (2021) is a case of good cooperation gone bad when German car manufacturers agreed to reduce the effectiveness of their jointly developed catalytic reduction technology AdBlue to only the bare minimum required by EU emission standards.
} 
petitive nature will typically create incentives for the members of these agreements to deviate, with different CSR efforts and production volumes than agreed upon, such defection would constitute a breach of contract that sufficiently large liabilities can prevent.

We begin by analyzing the baselines model in Section 4.1. In Sections 4.2 and 4.3, we subsequently show that our main result on the ranking of CSR efforts across the three types of joint agreements is robust to low willingness to pay with consumers for CSR, to CSR efforts affecting the marginal cost of production, and to firms being intrinsically motivated to invest in CSR in addition to their for-profit motives.

\subsection{Effective joint agreements}

Our main finding is that the CSR levels resulting from the three different types of joint CSR agreements compare as follows to the non-cooperative CSR level $v^{*}$, for all parameter values $(\alpha, \gamma, c, t, n)$.

Proposition 1. $v^{p}>v^{*}>v^{f}>v^{c s r}$.

Proof. See Appendix A.

Proposition 1 states that allowing agreements that directly involve CSR efforts leads to lower CSR levels than would result in the non-cooperative benchmark. When a group of firms increases their CSR levels by a given amount, their business stealing effects cancel out, but the costs of increased CSR remain. Therefore, when coordinating their CSR levels, firms reduce their CSR efforts and save on their investment costs. In contrast, a production agreement raises CSR efforts compared to the non-cooperative benchmark. A production agreement increases price-cost margins in the second stage of the game. These higher rents give the firms stronger business stealing incentives for investing in CSR in the first stage, as each additional customer is now worth more.

Proposition 1 holds for a wide class of demand systems. To see this, consider the reduced form profit in Stage 1 for any firm $i$

$$
\pi_{i}\left(\mathbf{q}(\mathbf{v}), v_{i}\right)
$$

where $\mathbf{q}(\mathbf{v})=q_{1}(\mathbf{v}), \ldots, q_{n}(\mathbf{v})$ are the conditional quantities, conditional on the choices of CSR in Stage 1, that solve Stage 2. In all four regimes $r \in\{*, c s r, p, f\}$, firm $i$ picks $v_{i}$ to maximize

$$
\pi_{i}\left(\mathbf{q}(\mathbf{v}), v_{i}\right)+\psi \sum_{i \neq j}^{n} \pi_{j}\left(\mathbf{q}(\mathbf{v}), v_{j}\right),
$$

where $\psi=1$ if CSR levels are chosen cooperatively in Stage 1 (in $r=c s r$ or $r=f$ ) and $\psi=0$ otherwise (in $r=*$ or $r=p$ ). 
If firms select quantities non-cooperatively in the Stage 2, then $\forall i, \frac{\partial \pi_{i}}{\partial q_{i}}=0$ and $q_{i}(\mathbf{v})=q_{i}^{*}(\mathbf{v})$, where $q_{i}^{*}(\mathbf{v})$ is the Nash-equilibrium conditional quantity. If firms select quantities cooperatively in Stage 2, then, $\sum_{i} \frac{\partial \pi_{i}}{\partial q_{j}}=0 \forall j$, and $q_{i}(\mathbf{v})=q_{i}^{c}(\mathbf{v})$, where $q_{i}^{c}(\mathbf{v})$ is the cooperative conditional quantity (in either $r=p$ or $r=f$, that is). The first-order condition for firm $i$ choosing $v_{i}$ in the non-cooperative benchmark is

$$
\sum_{i \neq j}^{n} \frac{\partial \pi_{i}}{\partial q_{j}} \frac{\partial q_{j}^{*}}{\partial v_{i}}+\frac{\partial \pi_{i}}{\partial v_{i}}=0
$$

For a CSR agreement, it is

$$
\sum_{i \neq j}^{n} \frac{\partial \pi_{i}}{\partial q_{j}} \frac{\partial q_{j}^{*}}{\partial v_{i}}+\frac{\partial \pi_{i}}{\partial v_{i}}+\sum_{i \neq j}^{n}\left(\sum_{i \neq j \neq k}^{n} \frac{\partial \pi_{j}}{\partial q_{k}} \frac{\partial q_{k}^{*}}{\partial v_{i}}+\frac{\partial \pi_{j}}{\partial q_{i}} \frac{\partial q_{i}^{*}}{\partial v_{i}}\right)=0,
$$

for a production agreement

$$
\sum_{i \neq j}^{n} \frac{\partial \pi_{i}}{\partial q_{j}} \frac{\partial q_{j}^{c}}{\partial v_{i}}+\frac{\partial \pi_{i}}{\partial v_{i}}+\frac{\partial \pi_{i}}{\partial q_{i}} \frac{\partial q_{i}^{c}}{\partial v_{i}}=0
$$

and for a full agreement

$$
\frac{\partial \pi_{i}}{\partial v_{i}}=0
$$

Equation (6) reveals the two incentives to invest in CSR that exist in the non-cooperative benchmark. The first term in equation (6) is the business stealing effect. By increasing its CSR level, a firm becomes relatively more attractive to consumers, and the quantity of all other firms decreases as a result. The second term in equation (6) is the demand effect, best seen in equation (2). Increasing its CSR level allows a firm to increase its price, holding quantity constant. Because firms select quantities to maximize their conditional profit in Stage 2, $\frac{\partial \pi_{i}}{\partial q_{i}}=0 \forall i$, implying that each firm ignores the effect of CSR investment on own profit mediated by changes in own quantity.

The terms in brackets in equation (7) show the additional (dis)incentives to invest in CSR that exist for a CSR agreement. For $n \geq 3$, the business stealing effect imposes both positive and negative externalities on the profit of the firms in a CSR agreement. Firm $i$ 's investment in CSR decreases firm $j$ 's profit by increasing firm $i$ 's quantity, but increases firm $j$ 's profit by reducing quantities of all firms $k(i \neq j \neq k)$. If $\left|\frac{\partial \pi_{j}}{\partial q_{i}} \frac{\partial q_{i}^{*}}{\partial v_{i}}\right|>$ $\sum_{i \neq j \neq k}^{n}\left|\frac{\partial \pi_{j}}{\partial q_{k}} \frac{\partial q_{k}^{*}}{\partial v_{i}}\right|$, the negative externality dominates and a CSR agreement reduces CSR levels compared to the non-cooperative benchmark. Intuitively, the requirement for $v^{*}>v^{c s r}$ is that firm i's CSR level influences firm $i$ 's quantity sufficiently more than it influences the quantity of all other firms.

A production agreement sets quantities cooperatively in Stage 2 such that $\sum_{i=1}^{n} \frac{\partial \pi_{i}}{\partial q_{j}}=$ $0 \forall j$. This implies that $\frac{\partial \pi_{i}}{\partial q_{i}}>0$, as $\frac{\partial \pi_{i}}{\partial q_{j}}<0(i \neq j)$. Firms in a production agreement take into account this positive effect of investing in CSR on own quantity, shown in 
the final term of equation (8). A production agreement increases price-cost margins, making it more profitable to attract extra consumers by investing in CSR. If $\left|\frac{\partial q_{j}^{c}}{\partial v_{i}}\right|$ is not too much smaller than $\left|\frac{\partial q_{j}^{*}}{\partial v_{i}}\right|(i \neq j)$, then it follows that $v^{p}>v^{*}$.

A full agreement controls both quantity and CSR levels, so that it completely eliminates the business stealing effect, and CSR investment is only driven by the demand effect. Equation (9) can be written as $\sum_{i \neq j}^{n} \frac{\partial \pi_{i}}{\partial q_{j}} \frac{\partial q_{j}^{*}}{\partial v_{i}}+\frac{\partial \pi_{i}}{\partial v_{i}}-\sum_{i \neq j}^{n} \frac{\partial \pi_{i}}{\partial q_{j}} \partial q_{j}^{*} \frac{\partial v_{i}}{\partial v^{*}}=0$. As long as $\frac{\partial \pi_{i}}{\partial q_{j}} \frac{\partial q_{j}^{*}}{\partial v_{i}}>0$, comparing equation (6) to equation (9) shows that $v^{*}>v^{f}$. If $\left|\frac{\partial \pi_{j}}{\partial q_{i}} \frac{\partial q_{i}^{*}}{\partial v_{i}}\right|-\sum_{i \neq j \neq k}^{n}\left|\frac{\partial \pi_{j}}{\partial q_{k}} \frac{\partial q_{k}^{*}}{\partial v_{i}}\right|>\left|\sum_{i \neq j}^{n} \frac{\partial \pi_{i}}{\partial q_{j}} \frac{\partial q_{j}^{*}}{\partial v_{i}}\right|$, we have $v^{f}>v^{c s r}$. This condition requires firm $i$ 's CSR level to influence firm $i$ 's demand sufficiently more than the demand of all other firms.

Hence, if raising CSR efforts is the goal, production agreements are the only type of joint agreement to consider allowing. However, competitors will not voluntarily form a production agreement if competition is too strong in the non-cooperative benchmark, as the following proposition shows. Let $\pi\left(q^{r}, v^{r}\right)$ denote profit in regime $r \in\{*, c s r, p, f\}$, where $q^{r}$ is the concomitant quantity.

Proposition 2. $\pi\left(q^{p}, v^{p}\right)>\pi\left(q^{*}, v^{*}\right)$ for $\gamma \leq \Gamma(n)$, or $\gamma>\Gamma(n)$ and $t>T(\gamma, n)$.

Proof. See Appendix A.

Firms only profit from engaging in a production agreement if their products are sufficiently differentiated or otherwise if investing in CSR is sufficiently expensive. ${ }^{26}$ If products are very similar $(\gamma>\Gamma(n))$ or investing in CSR is cheap $(t<T(\gamma, n))$, business stealing incentives are very high in production agreements. This causes firms to engage in an unprofitable 'arms race' in CSR efforts, as, in equilibrium, business stealing efforts between firms cancel out such that only the costs remain. ${ }^{27}$ Companies will not voluntarily form production agreements if this induces them to invest so much in CSR that profit is reduced compared to the non-cooperative benchmark.

Finally, we note that $\pi\left(q^{f}, v^{f}\right)>\pi\left(q^{p}, v^{p}\right)$ and $\pi\left(q^{f}, v^{f}\right)>\pi\left(q^{c s r}, v^{c s r}\right)$ always hold, confirming that firms allowed to coordinate on one dimension of competition between them are tempted to try to collude on the other(s) as well. It is straightforward that firms can always replicate the production or CSR agreement outcomes in a full agreement and do better by restricting their CSR investments and joint output, respectively. Such full elimination of competition would be illegal also under the policy to stimulate CSR by voluntary cooperative agreements - and therefore requires secrecy

\footnotetext{
${ }^{26}$ The exact expressions for the critical values of product homogeneity $\Gamma(n)$ and CSR costs $T(\gamma, n)$ are tedious and given in the proof of Proposition 2. They depend on $n$, with the parameter space where a production agreement benefits firms shrinking as $n$ increases.

${ }^{27}$ The possibility that firms over-invest in either cost-reducing R\&D or capacity in a non-cooperative first stage is also found in Fershtman and Gandal (1994), and Brod and Shivakumar (1999) when spillovers are low.
} 
and stabilization against the threat of unilateral defection, entry, and exit, which we leave aside. Nevertheless, if the risk of joint initiatives to promote companies taking more CSR sliding into full collusion is not strictly controlled, CSR levels may end up lower than in competition.

\subsection{Willingness to pay and CSR-dependent marginal costs}

Proponents of allowing firms to coordinate their CSR efforts have argued that collaboration is needed to increase CSR because consumers exhibit low, no, or even negative willingness to pay for the costly CSR efforts. ${ }^{28}$ A sufficiently high willingness to pay over CSR-related marginal cost increases would be needed for competition to be a stimulus for CSR efforts. ${ }^{29}$ In particular, firms in competition would be held back by a 'first-mover disadvantage' from unilaterally making investments in more responsible manufacturing, as this would decrease those firms' market shares and profitability. Only coordinated CSR investments would be able to break the deadlock. ${ }^{30}$ To study the validity of these arguments, we extend the baseline model with varying willingness to pay for CSR and CSR-dependent marginal costs.

Recall that market demand is positively related to CSR because consumers are assumed to be willing to pay more for products of firms with high CSR levels. In the market demand function (2), the price is assumed to increase one-to-one with the level of CSR effort $v_{i}$. To see what the effect is of lower or higher willingness to pay for CSR, consider the slightly more general demand system (denoted by superscript $\delta$ )

$$
p_{i}^{\delta}\left(\mathbf{q}, v_{i}\right)=\alpha+\beta v_{i}-q_{i}-\gamma \sum_{i \neq j}^{n} q_{j}, \quad i=1, \ldots, n,
$$

in which $\beta \geq 0$ scales the willingness to pay for CSR, that follows straightforwardly from multiplying $v_{i}$ in utility $(1)$ by $\beta$.

This generalization also allows for the analysis of cases in which CSR investments affect the marginal costs of production. Let the total marginal cost of production at CSR level $v_{i}$ be given by $c\left(1+\kappa v_{i}\right)$, in which $\kappa \geq 0(\kappa<0)$ is the increase (decrease) in the marginal costs of production resulting from higher CSR effort. As discussed in Section 1, CSR-induced marginal cost changes can be in either direction. While CSR terms such as better working conditions typically increase input costs, sustainable sourcing can increase access to funding and yield, and allow the company to pay lower interest rates and wages.

The profit of each firm $i$ can then be written as

$$
\pi_{i}^{\delta}\left(\mathbf{q}, v_{i}\right)=\left(\alpha+\delta v_{i}-q_{i}-\gamma \sum_{i \neq j}^{n} q_{j}-c\right) q_{i}-\frac{t v_{i}^{2}}{2}
$$

\footnotetext{
${ }^{28}$ One reason for low willingness to pay for CSR efforts could be that those efforts are imperfectly observable. Calveras and Ganuza (2018) study imperfectly observable CSR.

${ }^{29}$ See Dolmans (2021).

${ }^{30}$ Authority for Consumers and Markets (2021).
} 
where $\delta \equiv \beta-\kappa c$ is the net effect of willingness to pay for CSR and CSR-induced marginal cost changes on firm $i$ 's price-cost margin $p_{i}-c$. In the basic model that underlies Proposition 1, $\delta=1$ for simplicity. Obviously, for negligible cost increases, small values of $\delta$ reflect low willingness to pay for products of companies that take high CSR efforts. The value of $\delta$ remains positive as long as any marginal cost increases resulting from a higher CSR efforts are matched by a sufficiently strong consumer willingness to pay for them. Note that when $\delta \leq 0$, CSR levels only enter the profit function as a cost, so that no firm would invest in CSR regardless of the competitive regime.

From comparing CSR levels derived from the profit function in equation (11) across the four regimes, we find that their ranking is maintained - denoting the variation with subscript $\delta$.

Proposition 3. $v_{\delta}^{p}>v_{\delta}^{*}>v_{\delta}^{f}>v_{\delta}^{c s r}$ for all $\delta>0$.

Proof. See Appendix A.

The ranking op CSR levels given in Proposition 1 holds whenever consumers have at least some positive willingness to pay for more responsibly manufactured products over and above any marginal cost increase from the CSR advance, no matter how little that net willingness to pay is. When this is the case, corporations will each take more CSR efforts in competition than when they can coordinate their CSR actions.

The generality of this result can be seen again from the first-order conditions given in equations (6) to (9): these expressions are identical when $\delta>0$. Scaling the willingness to pay to CSR simply scales all incentives related to CSR, as is made precise in the following proposition.

Proposition 4. $\frac{\partial\left(v_{\delta}^{p}-v_{\delta}^{*}\right)}{\partial \delta}>0, \frac{\partial\left(v_{\delta}^{*}-v_{\delta}^{f}\right)}{\partial \delta}>0$, and $\frac{\partial\left(v_{\delta}^{f}-v_{\delta}^{c s r}\right)}{\partial \delta}>0$ for all $\delta>0$.

Proof. See Appendix A.

As a firm's price-cost margin increases, the differences between CSR levels in the different regimes increase. As $\delta$ scales the positive direct effect of CSR levels on profit, it also scales all incentives related to CSR. Increases in $\delta$ magnify the business stealing effect, further increasing incentives for CSR investments in a production agreement and decreasing incentives for CSR investments when firms coordinate such investments. If $\delta$ decreases, for instance due to increased marginal costs following CSR investments, the CSR levels in the different regimes converge and go to zero once $\beta$ becomes nonpositive.

The conclusion remains that CSR agreements do not stimulate CSR efforts compared to the non-cooperative benchmark: only production agreements do. There is no first-mover disadvantage due to "low" willingness to pay for the products and services 
of companies that take more social responsibility. Whenever firms can monetize their CSR efforts by attracting more business or increasing their margin, even if only a little, their incentives to invest in CSR are always stronger when they compete than when they are allowed to make CSR agreements. The crucial insight is that the difference in CSR efforts between competition and CSR cooperation is positive whenever there is a (net) positive willingness to pay. Moreover, if consumers have no positive (net) willingness to pay for CSR $(\delta \leq 0)$, coordination can never break any first-mover disadvantage deadlock as firms will never invest in CSR.

\subsection{Intrinsic motivation for CSR}

To study the extent to which intrinsic motivation for CSR affects our main findings, while by-passing principal-agent complexities or other issues that may be behind this motivation, we simply extend firm $i$ 's objective function with an additive term for direct CSR motivation. That is, let firm $i$ maximize

$$
\pi_{i}\left(\mathbf{q}, v_{i}\right)+\theta v_{i}
$$

in which $\theta \geq 0$ is a scaling parameter that expresses each firm's valuation of CSR for intrinsic reasons and $\pi_{i}\left(\mathbf{q}, v_{i}\right)$ is given by equation (3).

In Stage 2 of the game, nothing changes compared to the baseline model and the conditional quantities $v$ are still given by $q_{i}^{*}(\mathbf{v})$ if firms independently set quantities, and $q_{i}^{c}(\mathbf{v})$ if firms jointly set quantities. In Stage 1 of all four competitive regimes, firm $i$ now picks $v_{i}$ to maximize

$$
\pi_{i}\left(\mathbf{q}(\mathbf{v}), v_{i}\right)+\theta v_{i}+\psi \sum_{i \neq j}^{n}\left(\pi_{j}\left(\mathbf{q}(\mathbf{v}), v_{j}\right)+\theta v_{j}\right)
$$

where $\psi=1$ if CSR levels are chosen cooperatively in Stage 1, and $\psi=0$ otherwise. It is immediate from (13) that firms will invest more in CSR if they are intrinsically motivated than if they solely maximize profit $(\theta=0)$. The resulting CSR levels, denoted by a subscript $I$, compare as follows.

Proposition 5. $v_{I}^{p}>v_{I}^{*}>v_{I}^{f}>v_{I}^{c s r}$ for all $\theta>0$.

Proof. See Appendix A.

We find that the ranking of CSR levels across the different competitive regimes is unaffected when firms are also intrinsically motivated to increase CSR. Still, the only agreement that will increase CSR levels compared to the non-cooperative benchmark is a production agreement.

The reason for this is as follows. Adding $\theta$ to the left-hand side of the first-order conditions given in equations (6) to (9) gives the first-order conditions when firms are 
also intrinsically motivated. These conditions show that the added incentive to invest in CSR due to intrinsic motivation is identical for all competitive regimes. However, the lost profit from increasing CSR above the profit-maximizing level is not identical. In a production agreement, this lost profit is lowest as $\frac{\partial \pi_{i}}{\partial q_{i}}>0$ and $\frac{\partial q_{i}^{c}}{\partial v_{i}}>0$, so that the reduction in profit from pushing CSR efforts above the profit-maximizing amount is somewhat mitigated. For a CSR agreement, the lost profit of a given CSR increase is highest, as each CSR increase decreases profit for all members of the agreement, which is exactly the externality a CSR agreement is trying to avoid. Therefore, a CSR agreement will only slightly increase its CSR efforts for a given level of intrinsic motivation. A full agreement combines both effects, although the negative externality of CSR on the profit of all other firms in the agreement dominates. To see the generality of this result, note that the above arguments also carry through when intrinsic motivation is a smooth function of CSR, $f\left(v_{i}\right)$, in which case the term $\frac{\partial f\left(v_{i}\right)}{\partial v_{i}}$ is added to the left-hand side of first-order conditions (6) to (9).

The differences between the CSR levels of the different competitive regimes are increasing in the level of intrinsic motivation, as formalized in the next proposition.

Proposition 6. $\frac{\partial\left(v_{I}^{p}-v_{I}^{*}\right)}{\partial \theta}>0, \frac{\partial\left(v_{I}^{*}-v_{I}^{f}\right)}{\partial \theta}>0$, and $\frac{\partial\left(v_{I}^{f}-v_{I}^{c s r}\right)}{\partial \theta}>0$ for all $\theta>0$.

Proof. See Appendix A.

The stronger the direct motivation for CSR, the higher the CSR levels selected noncooperatively compared to CSR levels selected in coordination. The mechanisms underlying this result are those discussed in the previous paragraph. Therefore, allowing joint CSR agreements is an increasingly ineffective way of inducing CSR efforts when companies' intrinsic motivation becomes a more important driver of CSR efforts. This is true for all finite $\theta$ - for some sufficiently high value of which, of course, immediate profit become negative. At best, do all regimes converge on the same infinite CSR efforts - and infinite immediate losses - in the limit of $\theta$ going to infinity so that forprofit motivation is no longer part of a company's objective. We conclude that joint CSR agreements are never better than the competitive benchmark, not even when corporations are directly motivated to do good, however strongly. The incentives for CSR efforts remain greatest in a production agreement.

\section{Consumer and total welfare effects}

To analyze the welfare effects of the different types of joint agreements, we return to the baseline model $(\delta=1, \theta=0)$. Consumer welfare follows from substituting demand (2) into utility (1)

$$
C S(\mathbf{q})=\frac{1}{2}\left(\sum_{i=1}^{n} q_{i}^{2}+2 \gamma \sum_{i=1}^{n} \sum_{i>j} q_{i} q_{j}\right)
$$


Note that CSR does not directly affect consumer surplus because the additional utility from higher CSR efforts in equation (1) is cancelled out by matching price increases in demand (2). In this model, CSR levels only have an indirect effect on consumer welfare, through the way in which the firms' quantities depend on their CSR efforts. ${ }^{31}$ As quantities are symmetric, consumer surplus reduces to $C S\left(q^{r}\right)=\frac{n}{2}(\gamma(n-1)+$ 1) $\left(q^{r}\right)^{2}$, where $r \in\{*, c s r, p, f\}$, so that the ranking of consumer welfare across different competitive regimes corresponds to the ranking of quantities $q^{r} .{ }^{32}$

First we establish that joint agreements that fail to increase CSR efforts always harm consumers: $C S\left(q^{*}\right)>C S\left(q^{c s r}\right)>C S\left(q^{f}\right)$. A full agreement reduces consumer welfare on two accounts compared to the non-cooperative benchmark: it reduces conditional quantities in Stage 2 and CSR levels in Stage 1. A CSR agreement produces the noncooperative quantity conditional on CSR levels in in Stage 2, but reduces CSR levels in Stage 1, reducing consumer welfare on one account compared to the non-cooperative benchmark.

To compare a CSR agreement to a full agreement, first note that if CSR efforts are identical across firms and equal to $v$, conditional quantities are given by

$$
q^{*}(v)=\frac{A+v}{\gamma(n-1)+2} \text { and } q^{c}(v)=\frac{A+v}{2(\gamma(n-1)+1)}
$$

where $q^{*}(v)$ is the conditional quantity if firms select quantities non-cooperatively in Stage $2, q^{c}(v)$ is the conditional quantity if firms select quantities cooperatively in Stage 2, and $A=\alpha-c$. The difference in consumer surplus between a CSR agreement and the non-cooperative benchmark can be written as $\left|\frac{\partial C S}{\partial q} \frac{\partial q^{*}}{\partial v} \Delta v^{c s r}\right|$, where $\Delta v^{c s r}$ is $v^{c s r}-v^{*}<0$, and the difference in consumer surplus between a full agreement and the non-cooperative benchmark can be written as $\left|\frac{\partial C S}{\partial q}\left(\frac{\partial q^{c}}{\partial v} \Delta v^{f}+\Delta q^{f}\right)\right|$, where $\Delta v^{f}$ is $v^{f}-v^{*}<0$ and $\Delta q^{f}$ is $q^{f}\left(v^{*}\right)-q^{*}\left(v^{*}\right)<0$. As long as $\left|\frac{\partial q^{*}}{\partial v} \Delta v^{c s r}\right|<\left|\frac{\partial q^{c}}{\partial v} \Delta v^{f}+\Delta q^{f}\right|$, a full agreement reduces consumer surplus by more than a CSR agreement. In essence, unless benchmark quantities react very strongly to changes in CSR, a full agreement reduces consumers surplus by more than a CSR agreement.

Second, we note that the ranking of profit across these three regimes is opposite to that of consumer surplus for all parameter values: $\pi\left(q^{f}, v^{f}\right)>\pi\left(q^{c s r}, v^{c s r}\right)>\pi\left(q^{*}, v^{*}\right)$. Combined as total welfare in the market, defined for regime $r$ as

$$
W\left(q^{r}, v^{r}\right)=C S\left(q^{r}\right)+n \pi\left(q^{r}, v^{r}\right) .
$$

Let $W\left(q^{*}(v), v\right)$ denote welfare when all firms set quantities non-cooperatively and identical CSR levels $v$. We find that welfare compares as follows.

\footnotetext{
${ }^{31}$ For this reason, consumer surplus expression (14) follows equivalently from substituting demand (10) into the corresponding utility function (1), in which $v_{i}$ is multiplied by $\beta$. That is, consumer surplus does not directly depend on the willingness to pay consumers for CSR efforts.

${ }^{32}$ In Appendix C, we show that our findings on welfare are robust to allowing CSR levels to influence consumer welfare directly.
} 
Proposition 7. $W\left(q^{*}, v^{*}\right)>W\left(q^{c s r}, v^{c s r}\right)>W\left(q^{f}, v^{f}\right)$ and $\left.\frac{\partial W\left(q^{*}(v), v\right)}{\partial v}\right|_{v=v^{*}}>(<) 0$ if $\gamma<(>) \Gamma^{\prime}(n)$

Proof. See Appendix A.

Unsurprisingly, given Proposition 1, competition is unambiguously the superior regime amongst these three. It produces both higher CSR efforts and higher output, hence higher total within-market welfare. Proposition 7 also makes more precise in what sense competition should not be too strong, as mentioned in the introduction. When products are relatively homogeneous, beyond a critical level that decreases in the number of firms $(n)$, it is no longer possible to improve within-market total welfare by inducing more investments in CSR. That is, only when competition is sufficiently imperfect is the optimal CSR level in the market higher than the level in the non-cooperative benchmark. ${ }^{33}$

In case of production agreements, there is a trade-off: consumers benefit from increased CSR efforts, but are harmed from reduced output and therefore higher prices. However, we find that welfare is never served by allowing voluntary production agreements either. While a production agreement increases CSR efforts, it reduces consumer welfare compared to competition, except for a small set of well-chosen duopolies in which the firms would not voluntarily form the agreement. The following set of results establishes this.

Proposition 8. $C S\left(q^{*}\right)>C S\left(q^{p}\right)$, unless $n=2$ and $t<\frac{4-2 \gamma+\gamma^{2}}{2(1-\gamma)\left(4-\gamma^{2}\right)}$, in which case $C S\left(q^{*}\right)<C S\left(q^{p}\right)$ and $\pi\left(q^{*}, v^{*}\right)>\pi\left(q^{p}, v^{p}\right)$.

\section{Proof. See Appendix A.}

The first part of the proposition states that only when there are two firms and investing in CSR is sufficiently cheap, which is more often the case when goods are very similar ( $\gamma$ close to 1$)$, does a production agreement increase consumer welfare compared to the non-cooperative benchmark. Consumers are worse off with a production agreement in all other cases, despite the higher CSR levels.

The intuition for this result is as follows. A production agreement creates two opposing effects on consumer surplus. From Proposition 1 we know that in all cases $\Delta v^{p}=v^{p}-v^{*}>0$. Comparing conditional quantities (15) above shows that a production agreement reduces output conditional on CSR levels, and therefore $\Delta q^{p}=q^{c}\left(v^{*}\right)-$ $q^{*}\left(v^{*}\right)<0$. The total difference in consumer surplus between a production agreement and the non-cooperative benchmark is therefore given by $\left|\frac{\partial C S}{\partial q}\left(\frac{\partial q^{c}}{\partial v} \Delta v^{p}+\Delta q^{p}\right)\right|$. In

\footnotetext{
${ }^{33}$ We note that the socially optimal level of CSR is loss-making for the firms. The social optimum requires prices to equal marginal costs, and therefore firms make a loss after taking the fixed costs of CSR investment into account.
} 
a duopoly, if goods are similar and investing in CSR is cheap, $t<\frac{4-2 \gamma+\gamma^{2}}{2(1-\gamma)\left(4-\gamma^{2}\right)}$, the business stealing effect is very strong and $\Delta v^{p}$ becomes so large that the net effect on consumer surplus is positive. However, as $n$ increases, the responsiveness of quantity to CSR levels diminishes, and even when $\Delta v^{p c}$ is high, consumers are worse off compared to the non-cooperative benchmark.

To see the consumer welfare trade-off, note that the difference in total quantity between a production agreement and the non-cooperative benchmark, conditional on a fixed CSR level $\bar{v}$ is given by

$$
n\left(q^{*}(\bar{v})-q^{c}(\bar{v})\right)=(A+\bar{v}) \frac{\gamma n(n-1)}{2(\gamma(n-1)+2)(\gamma(n-1)+1)}
$$

which monotonically increases to $(A+\bar{v}) \frac{1}{2 \gamma}$ as $n$ goes to infinity. This implies that a production agreement hurts consumers by reducing conditional quantities regardless of market size, and that this negative effect on consumer surplus increases in $n$. From Proposition 1 we know that $v^{p}>v^{*}$, but whether this also results in increased consumer surplus depends on the responsiveness of quantity to CSR levels in both competitive regimes. The conditional quantities in equations (15) show that output is less responsive to CSR levels in a production agreement than in the non-cooperative benchmark and that this difference in responsiveness is increasing in $n$. In a duopoly, the responsiveness of quantity to CSR levels is highest, so high in fact that when investing is sufficiently cheap, a production agreement's CSR level might lead to a higher quantity compared to the non-cooperative benchmark. However, as $n$ increases, the responsiveness of quantity to CSR levels quickly drops off, and the reduction of conditional quantities eventually dominates the increase in CSR levels.

The trade-off between higher CSR levels and lower conditional quantities holds generally. However, the tipping point at $n=2$ is specific to this model. ${ }^{34}$ In these specific cases in which consumers could benefit from a production agreement, however, the companies prefer to compete instead, as business stealing incentives in a production agreement are so strong that over-investing in CSR reduces profit. Therefore, the only output agreements that simultaneously increase CSR efforts and consumer welfare will not be voluntarily engaged in by companies.

We conclude that no CSR agreement exists that simultaneously increases CSR efforts, consumer welfare and profit compared to the non-cooperative benchmark. Therefore, unconditionally allowing firms to coordinate their output volumes in order to advance CSR always decreases consumer surplus. In fact, in the baseline model, production agreements do not generate surplus wealth at all.

Proposition 9. $W\left(q^{*}, v^{*}\right)>W\left(q^{p}, v^{p}\right)$.

\footnotetext{
${ }^{34}$ In Appendix B we find that the tipping point occurs before $n=2$ when firms set prices instead of quantities in Stage 2, so that a production agreement can never increase consumer surplus compared to the non-cooperative benchmark.
} 
Proof. See Appendix A.

Propositions 7 and 9 together show that all types of joint agreements always reduce total within-market welfare. The reason is straightforward: any reduction of competition inescapably creates a deadweight loss.

\section{Exempting joint agreements from antitrust}

With joint output (or price) agreements being the only effective means to stimulate CSR efforts, the antitrust laws are a major obstacle to firm-led CSR initiatives. However, some competition authorities are opening up the idea of allowing, under conditions, anticompetitive agreements that promote CSR objectives. Most advanced is a framework to exempt sustainability agreements from the European cartel prohibition, Article 101 of the Treaty. Article 101 specifies four cumulative requirements for such an exemption. ${ }^{35}$ In essence, the advance of CSR should be (i) concrete and objectively measurable "economic progress", benefits of which (ii) consumers should receive "a fair share"The restrictions of competition should be (iii) "indispensable" for attaining the objectives, and should (iv) not eliminate competition on all dimensions in the market. In this section, we consider these principal legal requirements in light of our findings on joint agreements.

The focus of competition authorities that are open to permitting joint agreements, if they stimulate CSR, has been exclusively on agreements about CSR directly. Yet these we have found to reduce CSR efforts. At first sight, CSR agreements may appear sympathetic, and traditional price cartels may appear damaging. However, some reflection on the company's incentives has led to the insight that the opposite is true. Only production agreements can generate concrete CSR benefits, provided that consumers have (at least) some appreciation for the type of CSR efforts advanced - and otherwise, no agreement can. Therefore, if cartel law exemptions on CSR grounds are to be given at all, they must be for production agreements, not CSR agreements. In principle, this should be possible under the antitrust rules.

The second requirement, which is that consumers benefit, is more problematic. In its current interpretation in case law, the buyers of the products concerned are to be fully compensated, on average, for any anticompetitive effects that they suffer because of the agreement, by the benefits that the agreement brings about. ${ }^{36}$ Consumers should, in other words, not be worse off with the agreement in place. However, we find that no joint agreements exist that both increase CSR and consumer welfare, and that the companies would voluntarily engage in. Therefore, competition authorities would always need to strictly demand consumer compensation from firms allowed to form a production agreement, and ensure that this compensation is delivered. This fundamentally changes the agencies' market oversight role and requires information

\footnotetext{
${ }^{35}$ Article 101(3) TFEU lists these exemption conditions.

${ }^{36}$ See European Commission (2004) at recital 85/87.
} 
that they do not typically have available. Identifying genuine and effective CSR agreements, and monitoring them permanently, will be demanding on time and budget, and crowd out other important competition enforcement objectives. The policy presents a risk of abuse by companies colluding under the guise of corporate social responsibility.

Our model does offer a direct mechanism to make consumers indifferent: they can be given monetary compensation out of the firms' post-agreement profit directly via $m$ in utility function (1). However, by Proposition 9 there is no surplus wealth for full consumer compensation: total within-market welfare is lower under the production agreement than in competition. Compensation by redistributing profit is therefore not possible. In addition, requiring compensation reduces business stealing incentives, undermining the incentives to invest in CSR.

A competition authority that wants to accommodate a production agreement to induce CSR efforts will therefore have to give up the requirement that consumers be fully compensated and add benefits of the agreement to others who are not buyers of the products concerned. This is indeed the approach of the Dutch competition authority ACM - with a focus on "sustainability agreements". 37 The agency interprets "a fair share" as benefits that can be less than fully compensating and adds "out-of-marketefficiencies" or "externality benefits" that third parties to the agreement would obtain. The latter are easily many, since CSR efforts that reduce negative externalities, such as pollution or unfair trading, will be appreciated by many non-buyers who may also value CSR more than the actual consumers. ${ }^{38}$

To see the effects of including negative out-of-market externalities in our analysis, consider as externality

$$
E(\mathbf{q}, \mathbf{v})=\sum_{i=1}^{n} \frac{q_{i}}{v_{i}} .
$$

This expression has the appealing feature that for each firm, the increase of the negative externality due to producing one more unit of output is decreasing in that firm's CSR level. In addition, the marginal positive effect of a firm's CSR level on the externality that its production generates is decreasing in that firm's CSR level. Let the reduction of externalities in regime $r$ compared to the non-cooperative benchmark be $\Delta E\left(q^{r}, v^{r}\right)=n\left(\frac{q^{*}}{v^{*}}-\frac{q^{r}}{v^{r}}\right)$. These reductions compare across the different competitive regimes as follows.

Proposition 10. $\Delta E\left(q^{p}, v^{p}\right)>0>\Delta E\left(q^{f}, v^{f}\right)>\Delta E\left(q^{c s r}, v^{c s r}\right)$.

\section{Proof. See Appendix A.}

\footnotetext{
${ }^{37}$ Authority for Consumers and Markets (2021). Several other antitrust agencies are following suit, but not DG Competition, see European Commission (2021).

${ }^{38}$ In fact, so rich are benefits elsewhere likely to be, that a risk of this 'citizens' welfare standard' is that it will become hard for the competition authority to say no to production agreements at all. See Schinkel and Treuren (2021) for an elaborate discussion.
} 
Hence we find that adding out-of-market externality benefits does not justify joint agreements on CSR directly. CSR agreements increase negative externalities compared to the non-cooperative benchmark. Only production agreements decrease negative externalities. This is intuitive since a production agreement was found to be the only type of joint agreement that increases CSR efforts while at the same time reducing conditional quantities. $\Delta E\left(q^{p}, v^{p}\right)>0$ holds as long as externalities are increasing in output and decreasing in CSR. CSR agreements and full agreements also reduce output, but they decrease CSR levels. Which effect on negative externalities dominates depends on the relative weights given in the externality function to changes in CSR levels and changes in output. $\Delta E\left(q^{c s r}, v^{c s r}\right)<0$ and $\Delta E\left(q^{f}, v^{f}\right)<0$ hold more generally for externalities that increase in output and decrease in CSR efforts, as long as the externality is a function of $\frac{q^{r}}{v^{r}}$. The conclusion remains that if a joint agreement is exempted from cartel law at all, it better be a production agreement. Adding outof-market-efficiencies does not help to justify the exemption of CSR agreements.

The third requirement for a cartel exemption states that some competition must remain under the agreement, for example, on the dimensions of price, brand image, or technological development. Importantly, our result that production agreements can increase CSR efforts holds provided that competition on CSR remains, which should satisfy this requirement. In practice, agreements aimed at improving CSR efforts often involve only a subset of all firms in the market, leaving a competitive fringe. The existence of remaining competition in CSR efforts and output affects the incentives of the competitors that make joint agreements.

In Appendix D we show that our main findings on joint agreements still hold for partial agreements involving $m$ firms that leave remaining fringe competition $(m<n)$. Residual competition reduces the possibilities for firms to benefit from an agreement, which causes all outcomes to lie between the non-cooperative outcome and the outcome with a market-wide agreement. Therefore, partial agreements on CSR reduce CSR and output compared to the benchmark, but by less than market-wide agreements directly on CSR. Likewise, partial agreements on production increase CSR and reduce conditional quantities compared to the benchmark, but not as much as market-wide production agreements. Still, no agreement can profitably increase CSR levels and consumer welfare.

Finally, the fourth condition for a cartel exemption under Article 101(3) TFEU is that the restriction of competition must be necessary to obtain the benefits, in this case, CSR benefits. In practice, the interpretation of this indispensability requirement has been rather narrow - it suffices that the agreement does not go beyond what is necessary to generate the projected increase in CSR efforts compared to competition. This we have found to be the case only for production agreements. The condition may also be interpreted wider, as a broad duty of the competition authority to consider and prioritize alternative ways in which the projected CSR benefits could be achieved - particularly government regulation. In that case, a simple and far superior solution to excusing collusion exists in regulation, as follows.

For any industry-wide regulated CSR level $v>0$, let $W\left(q^{*}(v), v\right)$ be within-market 
welfare if the conditional quantities are set non-cooperatively, and let $W\left(q^{c}(v), v\right)$ be within-market welfare if the conditional quantities are set cooperatively (in either a production agreement or a full agreement).$^{39}$ We then obtain the following result.

Proposition 11. $W\left(q^{*}(v), v\right)>W\left(q^{c}(v), v\right)$ for all $v>0$.

Proof. See Appendix A.

The proposition establishes that welfare is always higher when the government simply mandates the CSR efforts that a production agreement would provide. The advance in CSR efforts that would result from a production agreement $\left(v^{p}>v^{*}\right)$, the government can simply demand by regulating CSR levels. Hence, there is no necessity to restrict competition to stimulate CSR. On the contrary: it is an inferior tool since any level of CSR that government deems an improvement $\left(v>v^{*}\right)$ it better simply imposes than left to an output-coordinating agreement. We do note that, since a regulated CSR level does not induce the same output restriction as a production agreement would, the reduction of negative externalities will typically be less with regulation than with a production agreement. However, governments can easily be more ambitious and set higher CSR goals to account for externalities.

\section{Concluding remarks}

Whenever consumers are more inclined to buy from companies with a stronger CSR profile, joint agreements on CSR turn out to reduce CSR efforts. The reason is that firms steal business from their rivals by showing CSR, and when firms jointly decide on their costly CSR efforts, this dimension of competition is eliminated. If incentives to invest in CSR need strengthening by reducing competition, coordination should not be permitted on CSR efforts directly, but only on output (or prices). Collusion on the output market stimulates CSR efforts indirectly: it increases profit per consumer, making it even more attractive for the firms to heighten their CSR profile and attract additional customers. Neither low willingness to pay for CSR with consumers, nor intrinsic motivations for CSR with firms, provide reasons to think that companies will increase their CSR investments if they can jointly decide on them. There is also no reason to expect more CSR efforts from private coordination if there is no willingness to pay for CSR.

We conclude that CSR agreements are better avoided altogether if the goal is to stimulate firms to take more responsibility for environmental and social objectives. These findings are in stark contrast to the business literature and practice calls claiming that collaboration would be imperative to stimulate CSR efforts. Our results should be

\footnotetext{
${ }^{39}$ Obviously, first allowing a CSR agreement and then regulating it to a higher CSR level makes little sense. With regulation, only the conditional quantities are relevant.
} 
a warning to all those who advocate collaborative CSR with the best intentions. The policy paradox is that society can only induce companies to invest more in CSR than they do in competition by allowing them to reap the benefits of their additional CSR efforts. Output agreements, however, raise competition law concerns and reduce the sum of consumer welfare and profit in the market. Therefore, compensating consumers for their antitrust damage is not possible. The latter is a requirement under the going interpretation of the European Treaty articles on horizontal agreements that thus cannot be met. Corporate appeals to collaborative CSR are best met with some reservations: competition is likely a stronger driver of CSR efforts than cooperation.

Our results also imply that government subsidies to stimulate CSR activities will not cause collaboration on CSR to increase CSR efforts. Per-unit subsidies based on a company's CSR efforts are equivalent to those CSR investments reducing marginal costs of production, which does not affect the ranking of CSR efforts across competitive regimes by Proposition 3. A lump-sum subsidy based on a firm's CSR profile, irrespective of its production level, is formally equivalent to how we modeled intrinsic motivation in equation (12). The ranking of CSR efforts is therefore unaffected by lump-sum CSR subsidies by Proposition 5. Naturally, if such subsidies were awarded conditional on the companies collaborating on CSR, investments in CSR will at some point increase compared to competition. In the case of contingent per-unit subsidies, this is comparable to collaboration-specific efficiencies on CSR efforts. It is not clear why permitting coordination is a good policy if it requires complementary CSR-specific subsidies to overcome the perverse CSR investment incentives it creates.

By its nature, CSR can have wider benefits than just within-market welfare, where it reduces negative production externalities such as pollution or human rights violations. Taking these out-of-market efficiencies into account may help justify voluntary production agreements in particular, as they increase CSR efforts and reduce output. ${ }^{40}$ However, permitting production agreements on these grounds is unprecedented in competition policy and comes with significant risks. Blurring the bright-line rule against hardcore price-fixing burdens competition authority and may undermine deterrence. A competition agency that does exempt a market agreement must permanently monitor that the companies involved indeed deliver on CSR and do not overcharge their customers. It will become increasingly difficult for the agency to know what CSR efforts would have been had regular competition been preserved. In addition to such greenwashing concerns, joint agreements on one aspect of competition carry risks of illegal collusion concerning other variables or markets, which may be harder to detect because of the existence of a platform for legal collaboration and possibly side-payments.

In favor of CSR agreements, it may be argued that there are spillovers from one company's CSR investments that benefit the others - rather than the firms being in pure CSR product quality competition. ${ }^{41}$ When such spillovers are significant, private

\footnotetext{
${ }^{40}$ The latter effect appeals to claims that fighting climate change requires reducing overconsumption, see Wiedmann et al. (2020).

${ }^{41}$ Spillovers can be modelled by replacing the intrinsic motivation factor $\theta v_{i}$ in equation (12) by $\sum_{j=1}^{n} \phi_{j} v_{j}$, where $\phi_{j}$ indicates the positive weight that firm $i$ puts on firm $j$ 's CSR efforts. Note,
} 
investments are discouraged as the benefits leak away to competitors, and a joint agreement on CSR could increase CSR efforts. However, to change our qualitative findings, spillovers must be large enough to counteract the negative incentive effect on CSR investments from eliminating business-stealing with more responsibly manufactured products, which always exist. ${ }^{42}$ As discussed in the introduction, it is unclear why there would be sizable spillovers in the cases concerned, which are about transitioning to known cleaner or fairer production methods. It does not suffice that firms may realize that they too will suffer from climate change or revolt against social injustices - not even as an existential threat. These global issues seem too immense for even the largest multinational companies to internalize sufficiently strongly.

Companies that are serious about their CSR better go ahead and competitively offer more responsibly produced goods rather than seek exemptions for anticompetitive agreements. Those who still perceive that they are discouraged from pursuing CSR initiatives by antitrust liability concerns are better advised to lobby their regulators to implement higher CSR standards. Here too, however, voluntary agreements have been identified as a possible strategic means to preempt future regulation. ${ }^{43}$ Government regulation seems to be superior to collaborative self-regulation. Before rushing ahead to relax the cartel laws based on unproven claims that collaboration would be needed to advance CSR, additional comparative study of regulatory approaches to CSR stimulation should be done.

Corporate social responsibility can play an important role in resolving pressing social problems, such as climate change and unfair business practices, that require urgent and drastic action that governments often fail to take. However, there is no compelling evidence that business collaboration in restraint of competition would induce companies to take this role. Instead, growing consumer awareness and increasing willingness to buy from and invest in companies serious about their CSR increasingly motivate firms to differentiate themselves from their competitors. Strategic CSR is a profitable business model and a hopeful gathering force for more responsible corporate behavior. Competition strengthens these incentives to do well by doing good, so that it is an engine for corporate social performance. It better be given free rein and not be throttled by corporate collaboration that risks collusion. While voluntary collective agreements have their merits in other contexts, such as creating R\&D synergies and setting standards, we submit that agreements on CSR efforts weaken competition as

however, that such an objective function implies that a firm would be strictly better off with a lower profit (possibly even a loss) and CSR level if its competitors invested enough in CSR. This seems hardly a sustainable business model, given the demands of owners and investors for a normal rate of return and regular industry dynamics.

${ }^{42}$ When this is the case, a 'first-mover disadvantage' occurs in the sense that firms unilaterally face no incentive to increase CSR above competitive levels, but jointly do. Production agreements then no longer increase CSR in our model.

${ }^{43}$ Lutz et al. (2000) show how self-regulated quality standards can weaken and delay better regulation. Innes and Sam (2008) finds that firms voluntarily reduce pollution in an attempt to relax future regulatory scrutiny. Malhotra et al. (2019) argue that firms can use modest private regulation to preempt more stringent public regulations. 
an important driver of corporate social efforts.

\section{References}

Aghion, P., Bénabou, R., Martin, R., and Roulet, A. (2020). Environmental preferences and technological choices: Is market competition clean or dirty? (no. w26921) National Bureau of Economic Research.

Ahmed, R. and Segerson, K. (2011). Collective voluntary agreements to eliminate polluting products. Resource and Energy Economics, 33(3):572-588.

Authority for Consumers and Markets (2021). Guidelines for sustainability agreements - Opportunities within competition law.

Azar, J., Duro, M., Kadach, I., and Ormazabal, G. (2021). The big three and corporate carbon emissions around the world. Journal of Financial Economics.

Bagnoli, M. and Watts, S. G. (2003). Selling to socially responsible consumers: Competition and the private provision of public goods. Journal of Economics \& Management Strategy, 12(3):419-445.

Bansal, P. and Roth, K. (2000). Why companies go green: A model of ecological responsiveness. Academy of Management Journal, 43(4):717-736.

Baron, D. P. (2001). Private politics, corporate social responsibility, and integrated strategy. Journal of Economics \& Management Strategy, 10(1):7-45.

Baron, D. P. (2007). Corporate social responsibility and social entrepreneurship. Journal of Economics \& Management Strategy, 16(3):683-717.

Bartling, B., Weber, R. A., and Yao, L. (2015). Do markets erode social responsibility? Quarterly Journal of Economics, 130(1):219-266.

Bénabou, R. and Tirole, J. (2010). Individual and corporate social responsibility. Economica, 77(305):1-19.

Besley, T. and Ghatak, M. (2007). Retailing public goods: The economics of corporate social responsibility. Journal of Public Economics, 91(9):1645-1663.

Brau, R. and Carraro, C. (2011). The design of voluntary agreements in oligopolistic markets. Journal of Regulatory Economics, 39(2):111-142.

Brod, A. and Shivakumar, R. (1999). Advantageous semi-collusion. Journal of Industrial Economics, 47(2):221-230.

Calveras, A. and Ganuza, J.-J. (2016). The role of public information in corporate social responsibility. Journal of Economics \&6 Management Strategy, 25(4):990-1017. 
Calveras, A. and Ganuza, J.-J. (2018). Corporate social responsibility and product quality. Journal of Economics \&6 Management Strategy, 27(4):804-829.

Car Emissions (2021). Commission Decision, Case AT.40178 - Car Emissions, 8 July.

Casadesus-Masanell, R., Crooke, M., Reinhardt, F., and Vasishth, V. (2009). Households' willingness to pay for "green" goods: Evidence from Patagonia's introduction of organic cotton sportswear. Journal of Economics 85 Management Strategy, 18(1):203-233.

CECED (1999). Commission Decision, Case IV.F.1/36.718 - CECED, 24 January.

Chatterji, A. K. and Toffel, M. W. (2019). Assessing the impact of CEO activism. Organization \& Environment, 32(2):159-185.

Cheng, B., Ioannou, I., and Serafeim, G. (2014). Corporate social responsibility and access to finance. Strategic Management Journal, 35(1):1-23.

Choné, P. and Linnemer, L. (2020). Linear demand systems for differentiated goods: Overview and user's guide. International Journal of Industrial Organization, 73:102663.

Consumer Detergents (2011). Commission Decision, Case COMP/39579 Consumer Detergents, 13 April.

d'Aspremont, C. and Jacquemin, A. (1988). Cooperative and noncooperative R\&D in duopoly with spillovers. American Economic Review, 78(5):1133-1137.

de Bettignies, J.-E., Liu, H. F., and Robinson, D. T. (2020). Corporate social responsibility and imperfect regulatory oversight: Theory and evidence from greenhouse gas emissions disclosures. (no. w28159) National Bureau of Economic Research.

Delmas, M. A. and Colgan, D. (2018). The Green Bundle. Stanford University Press.

Delmas, M. A. and Montes-Sancho, M. J. (2010). Voluntary agreements to improve environmental quality: Symbolic and substantive cooperation. Strategic Management Journal, 31(6):575-601.

Dewatripont, M. and Tirole, J. (2020). The morality of markets and the nature of competition. mimeo.

Ding, W., Levine, R., Lin, C., and Xie, W. (2020). Competition laws, norms and corporate social responsibility. (no. w27493) National Bureau of Economic Research.

Dolmans, M. (2021). Sustainable competition policy and the "polluter pays" principle. In Holmes, S., Middelschulte, D., and Snoep, M., editors, Competition Law, Climate Change $\&$ Environmental Sustainability. Concurrences. 
Du, S., Bhattacharya, C. B., and Sen, S. (2011). Corporate social responsibility and competitive advantage: Overcoming the trust barrier. Management Science, $57(9): 1528-1545$.

Duso, T., Röller, L.-H., and Seldeslachts, J. (2014). Collusion through joint R\&D: An empirical assessment. Review of Economics and Statistics, 96(2):349-370.

El Ghoul, S., Guedhami, O., Kwok, C. C., and Mishra, D. R. (2011). Does corporate social responsibility affect the cost of capital? Journal of Banking \& Finance, $35(9): 2388-2406$.

European Commission (2004). Guidelines on the application of Article 81(3) of the Treaty. Official Journal of the European Union, April 27.

European Commission (2021). Competition policy in support of Europe's green ambition. Competition policy brief 2021-01.

Falk, A. and Szech, N. (2013). Morals and markets. Science, 340(6133):707-711.

Fernández-Kranz, D. and Santaló, J. (2010). When necessity becomes a virtue: The effect of product market competition on corporate social responsibility. Journal of Economics \& Management Strategy, 19(2):453-487.

Fershtman, C. and Gandal, N. (1994). Disadvantageous semicollusion. International Journal of Industrial Organization, 12(2):141-154.

Fershtman, C. and Pakes, A. (2000). A dynamic oligopoly with collusion and price wars. RAND Journal of Economics, 31(2):207-236.

Flammer, C. (2015a). Does corporate social responsibility lead to superior financial performance? A regression discontinuity approach. Management Science, 61(11):2549 2568 .

Flammer, C. (2015b). Does product market competition foster corporate social responsibility? Evidence from trade liberalization. Strategic Management Journal, 36(10):1469-1485.

Friedman, M. (1970). A Friedman doctrine: The social responsibility of business is to increase its profits. The New York Times Magazine, September 13.

Gans, J. S. (2012). Innovation and climate change policy. American Economic Journal: Economic Policy, 4(4):125-45.

Gans, J. S. and Groves, V. (2012). Carbon offset provision with guilt-ridden consumers. Journal of Economics \& Management Strategy, 21(1):243-269.

Graafland, J. and Mazereeuw-Van der Duijn Schouten, C. (2012). Motives for corporate social responsibility. De Economist, 160(4):377-396. 
Hart, O. and Zingales, L. (2017a). Companies should maximize shareholder welfare not market value. Journal of Law, Finance, and Accounting, 2(2):247-275.

Hart, O. and Zingales, L. (2017b). Serving shareholders doesn't mean putting profit above all else. Harvard Business Review, 12:2-6.

Henderson, R. (2020). Reimagining Capitalism In A World On Fire. Public Affairs.

Holmes, S. (2020). Climate change, sustainability, and competition law. Journal of Antitrust Enforcement, 8(2):354-405.

Holmes, S., Middelschulte, D., and Snoep, M., editors (2021). Competition Law, Climate Change $\&$ Environmental Sustainability. Concurrences.

Hovenkamp, H. (2019). Are agreements to address climate change anticompetitive? The Regulatory Review, 11 September.

Ignatius, A. (2012). Captain planet. Harvard Business Review, 90(6):112-118.

Innes, R. and Sam, A. G. (2008). Voluntary pollution reductions and the enforcement of environmental law: An empirical study of the 33/50 program. Journal of Law and Economics, 51(2):271-296.

Kamien, M. I., Muller, E., and Zang, I. (1992). Research joint ventures and R\&D cartels. American Economic Review, 82(5):1293-1306.

Kerber, R. (2021). Investors BlackRock, Vanguard join net zero effort. Reuters, March 29.

Kitzmueller, M. and Shimshack, J. (2012). Economic perspectives on corporate social responsibility. Journal of Economic Literature, 50(1):51-84.

Kotchen, M. J. (2006). Green markets and private provision of public goods. Journal of Political Economy, 114(4):816-834.

Kotchen, M. J. and Segerson, K. (2019). On the use of group performance and rights for environmental protection and resource management. Proceedings of the National Academy of Sciences, 116(12):5285-5292.

Lenox, M. and Chatterji, A. K. (2018). Can Business Save The Earth? Innovating Our Way To Sustainability. Stanford University Press.

Lutz, S., Lyon, T. P., and Maxwell, J. W. (2000). Quality leadership when regulatory standards are forthcoming. Journal of Industrial Economics, 48(3):331-348.

Lyon, T. P. and Maxwell, J. W. (2004). Corporate Environmentalism and Public Policy. Cambridge University Press. 
Malhotra, N., Monin, B., and Tomz, M. (2019). Does private regulation preempt public regulation? American Political Science Review, 113(1):19-37.

Matsui, A. (1989). Consumer-benefited cartels under strategic capital investment competition. International Journal of Industrial Organization, 7(4):451-470.

McWilliams, A. and Siegel, D. (2001). Corporate social responsibility: A theory of the firm perspective. Academy of Management Review, 26(1):117-127.

Nidumolu, R., Ellison, J., Whalen, J., and Billman, E. (2014). The collaboration imperative. Harvard Business Review, 92(4):76-84.

Peloza, J. and Falkenberg, L. (2009). The role of collaboration in achieving corporate social responsibility objectives. California Management Review, 51(3):95-113.

Polman, P. and Winston, A. (2021). Net Positive: How Courageous Companies Thrive by Giving More Than They Take. Harvard Business Review Press.

Porter, M. and Kramer, M. (2006). Strategy and society: The link between competitive advantage and corporate social responsibility-response. Harvard Business Review, $85(5): 139$.

Salop, S. C. (1979). Monopolistic competition with outside goods. Bell Journal of Economics, 10(1):141-156.

Schinkel, M. P. and Spiegel, Y. (2017). Can collusion promote sustainable consumption and production? International Journal of Industrial Organization, 53:371-398.

Schinkel, M. P. and Tóth, L. (2019). Compensatory public good provision by a private cartel. Tinbergen Institute Discussion Paper TI 2019-086/VII.

Schinkel, M. P. and Treuren, L. (2021). Green antitrust: Friendly fire in the fight against climate change. In Holmes, S., Middelschulte, D., and Snoep, M., editors, Competition Law, Climate Change \& Environmental Sustainability. Concurrences.

Scott, I. (2016). Antitrust and socially responsible collaboration: A chilling combination. American Business Law Journal, 53(1):97-144.

Servaes, H. and Tamayo, A. (2013). The impact of corporate social responsibility on firm value: The role of customer awareness. Management Science, 59(5):1045-1061.

Sharfman, M. P. and Fernando, C. S. (2008). Environmental risk management and the cost of capital. Strategic Management Journal, 29(6):569-592.

Shleifer, A. (2004). Does competition destroy ethical behavior? American Economic Review, 94(2):414-418. 
Shubik, M. and Levitan, R. (1980). Market Structure and Behavior. Harvard University Press.

Simon, D. H. and Prince, J. T. (2016). The effect of competition on toxic pollution releases. Journal of Environmental Economics and Management, 79:40-54.

Symeonidis, G. (2000). Price and nonprice competition with endogenous market structure. Journal of Economics \&5 Management Strategy, 9(1):53-83.

Treuren, L. and Schinkel, M. P. (2018). Can collusion promote sustainable consumption and production? Not beneficially beyond duopoly. Amsterdam Center for Law and Economics. Working Paper No. 2018-01.

Wiedmann, T., Lenzen, M., Keyßer, L. T., and Steinberger, J. K. (2020). Scientists' warning on affluence. Nature Communications, 11(1):1-10. 


\section{Appendices}

\section{A Proofs of propositions}

Proof of Proposition 1. (Effective joint agreements) Define $A=\alpha-c, \beta_{1}=$ $\gamma(n-1)+2, \beta_{2}=\gamma(n-2)+2$, and $\beta_{3}=\gamma(n-3)+2$. In Stage 2, firms in the noncooperative benchmark or a CSR agreement maximize (3) with respect to $q_{i}$, resulting in Nash-equilibrium conditional quantities

$$
q_{i}^{*}(\mathbf{v})=\frac{\beta_{2}\left(A+v_{i}\right)-\gamma \sum_{i \neq j}^{n}\left(A+v_{j}\right)}{(2-\gamma) \beta_{1}}, \quad i=1, \ldots, n,
$$

while firms in a production agreement or a full agreement choose quantities to maximize the sum of members' profit, conditional on $\mathbf{v}$, resulting in conditional quantities (superscript $c$ for "coordinated")

$$
q_{i}^{c}(\mathbf{v})=\frac{(1-\gamma) A+\left(\beta_{2}-1\right) v_{i}-\gamma \sum_{i \neq j}^{n} v_{j}}{2(1-\gamma)\left(\beta_{1}-1\right)}, \quad i=1, \ldots, n .
$$

In Stage 1, firms in the non-cooperative benchmark pick $v_{i}$ to maximize $\pi_{i}\left(\mathbf{q}^{*}(\mathbf{v}), v_{i}\right)$, resulting in Nash-equilibrium CSR level

$$
v^{*}=A \frac{2 \beta_{2}}{t(2-\gamma) \beta_{1}^{2}-2 \beta_{2}} .
$$

Firms in a CSR agreement select $\mathbf{v}$ to maximize $\sum_{i=1}^{n} \pi_{i}\left(\mathbf{q}^{*}(\mathbf{v}), v_{i}\right)$ in Stage 1, resulting in CSR level

$$
v^{c s r}=A \frac{2}{t \beta_{1}^{2}-2} \text {. }
$$

Members of a production agreement determine $v_{i}$ by maximizing $\pi_{i}\left(\mathbf{q}^{c}(\mathbf{v}), v_{i}\right)$, so that the CSR level is

$$
v^{p}=A \frac{\beta_{3}}{4 t(1-\gamma)\left(\beta_{1}-1\right)-\beta_{3}} .
$$

A full agreement chooses $\mathbf{v}$ to maximize $\sum_{i=1}^{n} \pi_{i}\left(\mathbf{q}^{c}(\mathbf{v}), v_{i}\right)$ in Stage 1 . The resulting CSR level is

$$
v^{f}=A \frac{1}{2 t\left(\beta_{1}-1\right)-1} .
$$

Note that conditional quantities (18) and (19) are symmetric by implication. To ensure that all second-order conditions hold, and restricting our attention to interior solutions, in all proofs in this appendix we impose $8 t(1-\gamma)^{2}\left(\beta_{1}-1\right)-\beta_{3}^{2}>0$. The ranking 
follows from

$$
\begin{aligned}
v^{p}-v^{*} & =A \frac{\gamma^{2} t(n-1)\left(4 n+2 \gamma(n-1)(n-2)-\gamma^{2}(n-1)(n-3)\right)}{\left(4 t(1-\gamma)\left(\beta_{1}-1\right)-\beta_{3}\right)\left(t(2-\gamma) \beta_{1}^{2}-2 \beta_{2}\right)}>0, \\
v^{*}-v^{f} & =A \frac{\gamma t(1-n)(4+\gamma(2+\gamma)(n-1))}{\left(2 t\left(\beta_{1}-1\right)-1\right)\left(t(2-\gamma) \beta_{1}^{2}-2 \beta_{2}\right)}>0, \text { and } \\
v^{f}-v^{c s r} & =A \frac{t\left(\beta_{1}-2\right)^{2}}{\left(2 t\left(\beta_{1}-1\right)-1\right)\left(t \beta_{1}^{2}-2\right)}>0 .
\end{aligned}
$$

Proof of Proposition 2. (Profitability) Benchmark profit $\pi\left(q^{*}, v^{*}\right)$ is obtained by substituting equations (20) and (18) into equation (3). Profit in a production agreement, $\pi\left(q^{p}, v^{p}\right)$, is obtained by substituting (22) and (19) into equation (3). Comparing $\pi\left(q^{*}, v^{*}\right)$ to $\pi\left(q^{p}, v^{p}\right)$ shows that $\pi\left(q^{p}, v^{p}\right)>\pi\left(q^{*}, v^{*}\right)$ if $\gamma \leq \Gamma(n)$ or $\gamma>\Gamma(n)$ and $t>T(\gamma, n)$, and $\pi\left(q^{*}, v^{*}\right) \geq \pi\left(q^{p}, v^{p}\right)$ otherwise. Here, $T(\gamma, n)$ is given by

$$
\begin{aligned}
T(\gamma, n) & =\frac{1}{16}\left[\frac{16(1-2 n)}{n^{2}(\gamma-2)^{2}}-\frac{16(n-1)}{n^{3}(\gamma-2)}+\frac{(1+n)^{2}}{n(\gamma-1)^{2}}+\frac{n(n(n-5)+3)+1}{n^{2}(\gamma-1)}+\frac{(n-1)^{2}}{n^{2}\left(\beta_{1}-1\right)}+\frac{16}{n^{2} \beta_{1}^{2}}+\frac{16(n-1)^{2}}{n^{3} \beta_{1}}\right. \\
& \left.+\sqrt{\frac{\gamma^{2}\left(4 n+2 \gamma(n-1)(n-2)-\gamma^{2}(n-1)(n-3)\right)^{2}(\rho(\gamma, n))}{(\gamma-2)^{4}(\gamma-1)^{4}\left(\beta_{1}-1\right)^{2} \beta_{1}^{4}}}\right], \\
\rho(\gamma, n) & =256+128 \gamma(4 n-7)+16 \gamma^{2}(76+n(21 n-88))+80 \gamma^{3}(n-1)(n(n-8)+10)+4 \gamma^{4}(n-1)(n(n-31)+102) \\
& -4 \gamma^{5}(n-1)^{2}\left(n(n-13){ }_{1} 4\right)+\gamma^{6}\left(n^{2}-4 n+3\right)^{2} .
\end{aligned}
$$

and $\Gamma(n)$ is given by the 4 th smallest root of the following polynomial in $x$

$$
\begin{aligned}
f(x) & =32+x(64 n-192)+x^{2}\left(24 n^{2}-368 n+472\right)+x^{3}\left(-8 n^{3}-192 n^{2}+792 n-640\right)+x^{4}\left(-4 n^{4}-20 n^{3}+402 n^{2}-896 n+526\right) \\
& +x^{5}\left(4 n^{4}+60 n^{3}-372 n^{2}+580 n^{n}-272\right)+x^{6}\left(-n^{4}-40 n^{3}+162 n^{2}-200 n+79\right)+x^{7}\left(8 n^{3}-24 n^{2}+24 n-8\right) .
\end{aligned}
$$

Proof of Proposition 3. (Willingness to pay) In Stage 2, firms in the noncooperative benchmark or a CSR agreement maximize (11) with respect to $q_{i}$, resulting in Nash-equilibrium conditional quantities

$$
q_{\delta, i}^{*}(\mathbf{v})=\frac{\beta_{2}\left(A+\delta v_{i}\right)-\gamma \sum_{i \neq j}^{n}\left(A+\delta v_{j}\right)}{(2-\gamma) \beta_{1}}, \quad i=1, \ldots, n,
$$

while firms in a production agreement or a full agreement choose quantities to maximize the sum of members' profit, conditional on $\mathbf{v}$, resulting in conditional quantities

$$
q_{\delta, i}^{c}(\mathbf{v})=\frac{\left(\beta_{2}-1\right)\left(A+\delta v_{i}\right)-\gamma \sum_{i \neq j}^{n}\left(A+\delta v_{j}\right)}{2(1-\gamma)\left(\beta_{1}-1\right)} \quad i=1, \ldots, n .
$$

Let $\mathbf{q}_{\delta}^{*}=q_{\delta, 1}^{*}(\mathbf{v}), q_{\delta, 2}^{*}(\mathbf{v}), \ldots, q_{\delta, n}^{*}(\mathbf{v})$. In Stage 1 , firms in the non-cooperative benchmark pick $v_{i}$ to maximize $\pi_{i}\left(\mathbf{q}_{\delta}^{*}(\mathbf{v}), v_{i}\right)$, resulting in Nash-equilibrium CSR level

$$
v_{\delta}^{*}=A \frac{2 \delta \beta_{2}}{t(2-\gamma) \beta_{1}^{2}-2 \delta^{2} \beta_{2}} .
$$


A CSR agreement chooses $\mathbf{v}$ to maximize $\sum_{i=1}^{n} \pi_{i}\left(\mathbf{q}_{\delta}^{*}(\mathbf{v}), v_{i}\right)$ in Stage 1 , so that the CSR level is

$$
v_{\delta}^{c s r}=A \frac{2 \delta}{t \beta_{1}^{2}-2 \delta^{2}} \text {. }
$$

Let $\mathbf{q}_{\delta}^{c}=q_{\delta, 1}^{c}(\mathbf{v}), q_{\delta, 2}^{c}(\mathbf{v}), \ldots, q_{\delta, n}^{c}(\mathbf{v})$. Members of a production agreement determine $v_{i}$ by maximizing $\pi_{i}\left(\mathbf{q}_{\delta}^{c}(\mathbf{v}), v_{i}\right)$, so that the CSR level is

$$
v_{\delta}^{p}=A \frac{\delta \beta_{3}}{4 t(1-\gamma)\left(\beta_{1}-1\right)-\delta^{2} \beta_{3}} .
$$

Finally, a full agreement chooses $\mathbf{v}$ to maximize $\sum_{i=1}^{n} \pi_{i}\left(\mathbf{q}_{\delta}^{c}(\mathbf{v}), v_{i}\right)$ in Stage 1 . The resulting CSR level is

$$
v_{\delta}^{f}=A \frac{\delta}{2 t\left(\beta_{1}-1\right)-1} .
$$

The ranking follows from

$$
\begin{aligned}
v_{\delta}^{p}-v_{\delta}^{*} & =\delta A \frac{\gamma^{2} t(n-1)\left(4 n+2 \gamma(n-1)(n-2)-\gamma^{2}(n-1)(n-3)\right)}{\left(4 t(1-\gamma)\left(\beta_{1}-1\right)-\delta^{2} \beta_{3}\right)\left(t(2-\gamma) \beta_{1}^{2}-2 \delta^{2} \beta_{2}\right)}>0, \\
v_{\delta}^{*}-v_{\delta}^{f} & =\delta A \frac{\gamma t(1-n)(4+\gamma(2+\gamma)(n-1))}{\left(2 t\left(\beta_{1}-1\right)-\delta^{2}\right)\left(t(2-\gamma) \beta_{1}^{2}-2 \delta^{2} \beta_{2}\right)}>0, \text { and } \\
v_{\delta}^{f}-v_{\delta}^{c s r} & =\delta A \frac{t\left(\beta_{1}-2\right)^{2}}{\left(2 t\left(\beta_{1}-1\right)-\delta^{2}\right)\left(t \beta_{1}^{2}-2 \delta^{2}\right)}>0 .
\end{aligned}
$$

Proof of Proposition 4. (Polarization in willingness to pay) The difference $v_{\delta}^{p}-v_{\delta}^{*}$ is constructed from equations (28) and (26). Taking the derivative with respect to $\delta$ gives

$$
\frac{\partial\left(v_{\delta}^{p}-v_{\delta}^{*}\right)}{\partial \delta}=\frac{A \beta_{3}\left(4 t(1-\gamma)\left(\beta_{1}-1\right)+\delta^{2} \beta_{3}\right)}{\left(4 t(\gamma-1)\left(\beta_{1}-1\right)+\delta^{2} \beta_{3}\right)^{2}}+\frac{2 A \beta_{2}\left(t(\gamma-2) \beta_{1}^{2}-2 \delta^{2} \beta_{2}\right)}{\left(t(\gamma-2) \beta_{1}^{2}+2 \delta^{2} \beta_{2}\right)^{2}}>0 .
$$

The difference $v_{\delta}^{*}-v_{\delta}^{f}$ is constructed from equations (26) and (29). Taking the derivative with respect to $\delta$ gives

$$
\frac{\partial\left(v_{\delta}^{*}-v_{\delta}^{f}\right)}{\partial \delta}=\frac{2 A \beta_{2}\left(t(2-\gamma) \beta_{1}^{2}+2 \delta^{2} \beta_{2}\right)}{\left(t(\gamma-2) \beta_{1}^{2}+2 \delta^{2} \beta_{2}\right)^{2}}-\frac{A\left(\delta^{2}+2 t\left(\beta_{1}-1\right)\right)}{\left(\delta^{2}-2 t\left(\beta_{1}-1\right)\right)^{2}}>0 .
$$

The difference $v_{\delta}^{f}-v_{\delta}^{c s r}$ is constructed from equations (29) and (27). Taking the derivative with respect to $\delta$ gives

$$
\frac{\partial\left(v_{\delta}^{f}-v_{\delta}^{c s r}\right)}{\partial \delta}=\frac{A\left(\delta^{2}+2 t\left(\beta_{1}-1\right)\right)}{\left(\delta^{2}-2 t\left(\beta_{1}-1\right)\right)^{2}}-\frac{2 A\left(t \beta_{1}^{2}+2 \delta^{2}\right)}{\left(t \beta_{1}^{2}-2 \delta^{2}\right)^{2}}>0 .
$$


Proof of Proposition 5. (Intrinsic motivation) Intrinsic motivation does not affect the conditional quantities that solve Stage 2 of the game. In Stage 2, firm $i$ in the non-cooperative benchmark or a CSR agreement maximizes objective function (12) with respect to $q_{i}$, resulting in conditional quantity given by equation (18). Firm $i$ in a production agreement or a full agreement choose quantities to maximize $\sum_{i=1}^{n}\left(\pi_{i}\left(\mathbf{q}, v_{i}\right)+\theta v_{i}\right)$ resulting in conditional quantity given by equation (19).

In Stage 1 , firms in the non-cooperative benchmark pick $v_{i}$ to maximize $\pi_{i}\left(\mathbf{q}^{*}(\mathbf{v}), v_{i}\right)+$ $\theta v_{i}$, resulting in Nash-equilibrium CSR level

$$
v_{I}^{*}=v^{*}+\frac{(2-\gamma) \beta_{1}^{2} \theta}{t(2-\gamma) \beta_{1}^{2}-2 \beta_{2}}=\frac{2 \beta_{2} A+(2-\gamma) \beta_{1}^{2} \theta}{t(2-\gamma) \beta_{1}^{2}-2 \beta_{2}} .
$$

Firms in a CSR agreement choose $\mathbf{v}$ to maximize $\sum_{i=1}^{n}\left(\pi_{i}\left(\mathbf{q}^{*}(\mathbf{v}), v_{i}\right)+\theta v_{i}\right)$ in Stage 1, with the resulting CSR level given by

$$
v_{I}^{c s r}=v^{c s r}+\frac{\beta_{1}^{2} \theta}{t \beta_{1}^{2}-2}=\frac{2 A+\beta_{1}^{2} \theta}{t \beta_{1}^{2}-2} .
$$

The members of a production agreement determine $v_{i}$ by maximizing $\pi_{i}\left(\mathbf{q}^{c}(\mathbf{v}), v_{i}\right)+\theta v_{i}$, so that the CSR level is

$$
v_{I}^{p}=v^{p}+\frac{4(1-\gamma)\left(\beta_{1}-1\right) \theta}{4 t(1-\gamma)\left(\beta_{1}-1\right)-\beta_{3}}=\frac{\beta_{3} A+4(1-\gamma)\left(\beta_{1}-1\right) \theta}{4 t(1-\gamma)\left(\beta_{1}-1\right)-\beta_{3}} .
$$

Finally, firms in a full agreement choose $\mathbf{v}$ to maximize $\sum_{i=1}^{n}\left(\pi_{i}\left(\mathbf{q}^{c}(\mathbf{v}), v_{i}\right)+\theta v_{i}\right)$ in Stage 1. The resulting CSR level is

$$
v_{I}^{f}=v^{f}+\frac{2\left(\beta_{1}-1\right) \theta}{2 t\left(\beta_{1}-1\right)-1}=\frac{A+2\left(\beta_{1}-1\right) \theta}{2 t\left(\beta_{1}-1\right)-1} .
$$

The ranking follows from

$$
\begin{aligned}
v_{I}^{p}-v_{I}^{*} & =(A t+\theta) \frac{\gamma^{2}(n-1)\left(\gamma^{2}(n-1)(n-3)-2 \gamma(n-1)(n-2)-4 n\right)}{\left(4 t(\gamma-1)\left(\beta_{1}-1\right)+\beta_{3}\right)\left(t(2-\gamma) \beta_{1}^{2}-2 \beta_{2}\right)}>0, \\
v_{I}^{*}-v_{I}^{f} & =(A t+\theta) \frac{\gamma(n-1)(\gamma(2+\gamma)(n-1)+4)}{\left(2 t\left(\beta_{1}-1\right)-1\right)\left(t(2-\gamma) \beta_{1}^{2}-2 \beta_{2}\right)}>0, \text { and } \\
v_{I}^{f}-v_{I}^{c s r} & =(A t+\theta) \frac{\gamma^{2}(n-1)^{2}}{\left(2 t\left(\beta_{1}-1\right)-1\right)\left(t \beta_{1}^{2}-2\right)}>0 .
\end{aligned}
$$

Proof of Proposition 6. (Polarization in intrinsic motivation) The difference $v_{I}^{p}-v_{I}^{*}$ is constructed from equations (32) and (30). Taking the derivative with respect to $\theta$ gives

$$
\frac{\partial\left(v_{I}^{p}-v_{I}^{*}\right)}{\partial \theta}=\frac{\gamma^{2}(n-1)\left(4 n+2 \gamma(n-1)(n-2)-\gamma^{2}(n-1)(n-3)\right)}{\left(4 t(\gamma-1)\left(\beta_{1}-1\right)+\beta_{3}\right)\left(t(\gamma-2) \beta_{1}^{2}+2 \beta_{2}\right)}>0 .
$$


The difference $v_{I}^{*}-v_{I}^{f}$ is constructed from equations (30) and (33). Taking the derivative with respect to $\theta$ gives

$$
\frac{\partial\left(v_{I}^{*}-v_{I}^{f}\right)}{\partial \theta}=\frac{\gamma(1-n)(\gamma(2+\gamma)(n-1)+4)}{\left(2 t\left(\beta_{1}-1\right)-1\right)\left(t(\gamma-2) \beta_{1}^{2}+2 \beta_{2}\right)}>0 .
$$

The difference $v_{I}^{f}-v_{I}^{c s r}$ is constructed from equations (33) and (31). Taking the derivative with respect to $\theta$ gives

$$
\frac{\partial\left(v_{I}^{f}-v_{I}^{c s r}\right)}{\partial \theta}=\frac{\gamma^{2}(n-1)^{2}}{\left(2 t\left(\beta_{1}-1\right)-1\right)\left(t \beta_{1}^{2}-2\right)}>0 .
$$

Proof of Proposition 7. (Welfare CSR agreements) Substituting equations (18) and (20) into equations (3) and (14), and then adding total profit of all firms to consumer surplus gives Nash-equilibrium welfare in the non-cooperative benchmark

$$
W\left(q^{*}, v^{*}\right)=A^{2} n t \frac{t(\gamma-2)^{2}\left(\beta_{1}+1\right) \beta_{1}^{2}-4 \beta_{2}^{2}}{2\left(t(\gamma-2) \beta_{1}^{2}+2 \beta_{2}\right)^{2}} .
$$

Substituting equations (18) and (21) into equations (3) and (14), and then adding total profit of all firms to consumer surplus gives welfare in a CSR agreement

$$
W\left(q^{c s r}, v^{c s r}\right)=A^{2} n t \frac{t\left(\beta_{1}+1\right) \beta_{1}^{2}-4}{2\left(t \beta_{1}^{2}-2\right)^{2}} .
$$

Substituting equations (19) and (23) into equations (3) and (14), and then adding total profit of all firms to consumer surplus gives welfare in a full agreement

$$
W\left(q^{f}, v^{f}\right)=A^{2} n t \frac{3 t\left(\beta_{1}-1\right)-1}{2\left(2 t\left(\beta_{1}-1\right)-1\right)^{2}} .
$$

Straightforward calculations deliver $W\left(q^{*}, v^{*}\right)-W\left(q^{c s r}, v^{c s r}\right)>0$, and $W\left(q^{c s r}, v^{c s r}\right)-$ $W\left(q^{f}, v^{f}\right)>0$.

Imposing $v_{i}=v \forall i$, substituting equation (18) into equation (3) and equation (14), and adding total profit of all firms to consumer surplus gives

$$
W\left(q^{*}(v), v\right)=\frac{n\left(3 A^{2}+6 A v+\gamma(n-1)(A+v)^{2}-\left(t \beta_{1}^{2}-3\right) v^{2}\right)}{2 \beta_{1}^{2}} .
$$

Taking the derivative of equation (37) with respect to $v$, and then imposing $v=v^{*}$ gives

$$
\left.\frac{\partial W\left(q^{*}(v), v\right)}{\partial v}\right|_{v=v^{*}}=\operatorname{Ant} \frac{\gamma\left(\beta_{1}-1\right)-2}{t(\gamma-2) \beta_{1}^{2}+2 \beta_{2}}
$$

where $\left.\frac{\partial W\left(q^{*}(v), v\right)}{\partial v}\right|_{v=v^{*}} \geq 0$ if $\gamma \leq \Gamma^{\prime},\left.\frac{\partial W\left(q^{*}(v), v\right)}{\partial v}\right|_{v=v^{*}}<0$ if $\gamma>\Gamma^{\prime}$, and $\Gamma^{\prime}=\frac{1}{2} \sqrt{\frac{8 n-7}{(n-1)^{2}}}-$ $\frac{1}{2(n-1)}$. 
Proof of Proposition 8. (Consumer welfare production agreement) In competitive regime $r, r \in\{*, c s r, p, f\}$, consumer surplus (14) can be written as $C S\left(q^{r}\right)=$ $\frac{n}{2}(\gamma(n-1)+1)\left(q^{r}\right)^{2}$ as quantities and CSR levels are symmetric. Therefore, the ranking of consumer surpluses is equivalent to that of quantities. We have

$$
q^{p}-q^{*}=A t \frac{\gamma(1-n)\left(2 t(\gamma-2)(\gamma-1) \beta_{1}+\gamma(\gamma-2)(n-3)-4\right)}{\left(4 t(\gamma-1)\left(\beta_{1}-1\right)+\beta_{3}\right)\left(t(\gamma-2) \beta_{1}^{2}+2 \beta_{2}\right)}
$$

which is always negative for $n>2$, and positive for $n=2$ as long as $t<\frac{4-2 \gamma+\gamma^{2}}{2(1-\gamma)\left(4-\gamma^{2}\right)}$. Nash-equilibrium profit of a firm in the non-cooperative benchmark follows from substituting equations (18) and (20) into equation (3)

$$
\pi\left(q^{*}, v^{*}\right)=A^{2} t \frac{t(\gamma-2)^{2} \beta_{1}^{2}-2 \beta_{2}^{2}}{\left(t(\gamma-2) \beta_{1}^{2}+2 \beta_{2}\right)^{2}} .
$$

Profit of a firm in a production agreement follows from substituting equations (19) and (22) into equation (3)

$$
\pi\left(q^{p}, v^{p}\right)=A^{2} t \frac{8 t(\gamma-1)^{2}\left(\beta_{1}-1\right)-\beta_{3}^{2}}{2\left(4 t(\gamma-1)\left(\beta_{1}-1\right)+\beta_{3}\right)^{2}} .
$$

Imposing $n=2$ and $t<\frac{4-2 \gamma+\gamma^{2}}{2(1-\gamma)\left(4-\gamma^{2}\right)}$ gives $\pi\left(q^{*}, v^{*}\right)>\pi\left(q^{p}, v^{p}\right)$.

Proof of Proposition 9. (Welfare production agreement) Substituting equations (19) and (22) into equations (3) and (14), and then adding total profit of all firms to consumer surplus gives welfare in a production agreement

$$
W\left(q^{p}, v^{p}\right)=A^{2} n t \frac{12 t(\gamma-1)^{2}\left(\beta_{1}-1\right)-\beta_{3}^{2}}{2\left(4 t(\gamma-1)\left(\beta_{1}-1\right)+\beta_{3}\right)^{2}} .
$$

Comparing equation (34) to equation (40) shows that $W\left(q^{*}, v^{*}\right)>W\left(q^{p}, v^{p}\right)$.

Proof of Proposition 10. (Externalities) We have $E\left(q^{r}, v^{r}\right)=n \frac{q^{r}}{v^{r}}, r \in\{*, c s r, p, f\}$, as quantities and CSR levels are symmetric, so that the ranking of externalities across competitive regimes corresponds to the ranking of the ratio of quantity to CSR level. Substituting equations (18) to (23) in $E\left(q^{r}, v^{r}\right)$ and taking differences gives

$$
\begin{aligned}
E\left(q^{c s r}, v^{c s r}\right)-E\left(q^{f}, v^{f}\right) & =\frac{\gamma \operatorname{tn}(n-1)}{2}>0, \\
E\left(q^{f}, v^{f}\right)-E\left(q^{*}, v^{*}\right) & =\frac{\gamma^{2} \operatorname{tn}(n-1)}{2 \beta_{2}}>0, \text { and } \\
E\left(q^{*}, v^{*}\right)-E\left(q^{p}, v^{p}\right) & =\frac{\gamma \operatorname{tn}(n-1)(\gamma(2-\gamma)(n-3)+4)}{2 \beta_{2} \beta_{3}}>0,
\end{aligned}
$$

from which the ranking follows. 
Proof of Proposition 11. (Regulation) Substituting equation (18) into equations (3) and (14), imposing $v_{i}=v \forall i$, and adding total profit of all firms to consumer surplus, gives welfare when quantities are chosen non-cooperatively and CSR levels are regulated to $v$

$$
W\left(q^{*}(v), v\right)=n \frac{3 A^{2}+6 A v+\left(3-4 t\left(\beta_{1}-1\right)\right) v^{2}}{8\left(\beta_{1}-1\right)} .
$$

Substituting equation (19) into equations (3) and (14), imposing $v_{i}=v \forall i$, and adding total profit of all firms to consumer surplus, gives welfare when quantities are chosen cooperatively and CSR levels are regulated to $v$

$$
W\left(q^{c}(v), v\right)=n \frac{3 A^{2}+6 A v+\gamma(n-1)(A+v)^{2}+\left(3-t \beta_{1}^{2}\right) v^{2}}{2 \beta_{1}^{2}} .
$$

Subtracting equation (42) from equation (41) gives

$$
W\left(q^{*}(v), v\right)-W\left(q^{c}(v), v\right)=(A+v)^{2} \frac{\gamma n(n-1)\left(\beta_{1}+2\right)}{8\left(\beta_{1}-1\right) \beta_{1}^{2}}>0 .
$$

\section{B Price setting}

In this appendix, we verify that our results on CSR levels carry through when firms set prices in Stage 2 instead of quantities. An agreement in Stage 2 only, now titled a "price agreement", remains the sole agreement that increases CSR levels compared to the non-cooperative benchmark. As in the baseline model, price agreements increase CSR because coordination in the product market increases the profit margin per consumer, increasing incentives to attract additional consumers by investing in CSR. Consumer welfare results are different when firms set prices in Stage 2 of the game. In this setting, all agreements always reduce consumer welfare. The reason is primarily that, with price setting, the non-cooperative benchmark becomes more competitive and consumer welfare increases compared to the quantity setting benchmark in the main text. Therefore, the reduction in consumer welfare due to a price agreement increasing conditional prices can never be offset by higher CSR levels. As with quantity setting, taking out-of-market externalities into account can justify a price agreement on total welfare grounds when firms set prices in Stage 2, as long as the externalities get sufficient weight in the welfare function.

We start by deriving the profit function of the price setting game. Summing over all firms, demand (2) is

$$
\sum_{i=1}^{n} p_{i}=\sum_{i=1}^{n}\left(\alpha+v_{i}\right)-\left(\beta_{1}-1\right) \sum_{i=1}^{n} q_{i} .
$$

Noting that $\sum_{i \neq j}^{n} q_{j}=\sum_{k=1}^{n} q_{k}-q_{i}$, and substituting for $\sum_{i \neq j}^{n} q_{j}$ into equation (2), the quantity of each firm $i$ can be written as

$$
q_{i}(\mathbf{p}, \mathbf{v})=\frac{\left(\beta_{2}-1\right)\left(\alpha+v_{i}-p_{i}\right)-\gamma \sum_{i \neq j}^{n}\left(\alpha+v_{j}-p_{j}\right)}{(1-\gamma)\left(\beta_{1}-1\right)}
$$


where $\mathbf{p}=p_{1}, p_{2}, \ldots, p_{n}$. The profit of each firm $i$ is given by

$$
\pi_{i}(\mathbf{p}, \mathbf{v})=\left(p_{i}-c\right)\left(\frac{\left(\beta_{2}-1\right)\left(\alpha+v_{i}-p_{i}\right)-\gamma \sum_{i \neq j}^{n}\left(\alpha+v_{j}-p_{j}\right)}{(1-\gamma)\left(\beta_{1}-1\right)}\right)-\frac{t v_{i}^{2}}{2} .
$$

Equation (45) makes clear that each firm's profit is directly affected by the CSR levels of all other firms, in contrast to the quantity setting game where profit (3) depends only on the other firms' CSR levels indirectly through the conditional quantities that solve Stage 2 of the game. Firms play a two-stage game. In Stage 1 each firm selects its CSR level $v_{i}$. In Stage 2, given CSR levels $\mathbf{v}$, each firm selects its price $p_{i}$.

Comparing CSR levels - denoting the price setting game with subscript $B$ - across the four competitive regimes gives.

Proposition B1 $v_{B}^{p}>v_{B}^{*}>v_{B}^{f}>v_{B}^{c s r}$.

Proof. In Stage 2, firms in the non-cooperative benchmark or a CSR agreement maximize (45) with respect to $p_{i}$, resulting in Nash-equilibrium conditional price of firm $i$

$p_{i}^{*}(\mathbf{v})=\frac{\left(\beta_{3}\left(\beta_{2}-1\right)+\gamma(1-\gamma)\right)\left(\alpha+v_{i}\right)-\gamma\left(\beta_{2}-1\right) \sum_{i \neq j}^{n}\left(\alpha+v_{j}\right)+(\gamma(2 n-3)+2)\left(\beta_{2}-1\right) c}{(\gamma(2 n-3)+2) \beta_{3}}$,

while firms in a price agreement or a full agreement choose prices to maximize the sum of members' profit, conditional on $\mathbf{v}$, resulting in conditional price

$$
p_{i}^{c}\left(v_{i}\right)=\frac{\alpha+v_{i}+k}{2}, \quad i=1, \ldots, n
$$

Let $\mathbf{p}^{*}(\mathbf{v})=p_{1}^{*}(\mathbf{v}), p_{2}^{*}(\mathbf{v}), \ldots, p_{n}^{*}(\mathbf{v})$. In Stage 1, firms in the non-cooperative benchmark pick $v_{i}$ to maximize $\pi_{i}\left(\mathbf{p}^{*}(\mathbf{v}), \mathbf{v}\right)$, resulting in Nash-equilibrium CSR level

$$
v_{B}^{*}=A \frac{2(\gamma(n-2)+1)\left(\gamma^{2} n^{2}-5 \gamma^{2} n+5 \gamma^{2}+3 \gamma n-6 \gamma+2\right)}{t(\gamma(2 n-3)+2)\left(\beta_{1}-1\right) \beta_{3}^{2}-2(\gamma(n-2)+1)\left(\gamma^{2} n^{2}-5 \gamma^{2} n+5 \gamma^{2}+3 \gamma n-6 \gamma+2\right)} .
$$

Firms in a CSR agreement select $\mathbf{v}$ to maximize $\sum_{i=1}^{n} \pi_{i}\left(\mathbf{p}^{*}(\mathbf{v}), \mathbf{v}\right)$ in Stage 1 , resulting in CSR level

$$
v_{B}^{c s r}=A \frac{2(1-\gamma)\left(\beta_{2}-1\right)}{t\left(\beta_{1}-1\right) \beta_{3}^{2}-2(1-\gamma)\left(\beta_{2}-1\right)} .
$$

Let $\mathbf{p}^{c}(\mathbf{v})=p_{1}^{c}\left(v_{1}\right), p_{2}^{c}\left(v_{2}\right), \ldots, p_{n}^{c}\left(v_{n}\right)$. Members of a price agreement determine $v_{i}$ by maximizing $\pi_{i}\left(\mathbf{p}^{c}(\mathbf{v}), \mathbf{v}\right)$, so that the CSR level is

$$
v_{B}^{p}=A \frac{\beta_{3}}{4 t(1-\gamma)\left(\beta_{1}-1\right)-\beta_{3}}
$$


A full agreement chooses $\mathbf{v}$ to maximize $\sum_{i=1}^{n} \pi_{i}\left(\mathbf{p}^{c}(\mathbf{v}), \mathbf{v}\right)$ in Stage 1. The resulting CSR level is

$$
v_{B}^{f}=A \frac{1}{2 t\left(\beta_{1}-1\right)-1} .
$$

Note that conditional prices (46) and (47) are symmetric by implication. To ensure that all second-order conditions hold, and restricting our attention to interior solutions, in all proofs in this appendix we impose $8 t(1-\gamma)^{2}\left(\beta_{1}-1\right)-\beta_{3}^{2}>0$. The ranking follows from

$$
\begin{aligned}
v_{B}^{p}-v_{B}^{*} & =A \frac{t \gamma^{2}(1-n)\left(\beta_{1}-1\right)\left(\gamma^{2}(n(n-2)(2 n-7)-1)+2 \gamma n(3 n-7)+4 n\right)}{\left(4 t(\gamma-1)\left(\beta_{1}-1\right)+\beta_{3}\right)\left(t(\gamma(2 n-3)+2)\left(\beta_{1}-1\right) \beta_{3}^{2}-2\left(\beta_{2}-1\right)(\gamma(n(\gamma(n-5)+3)+5 \gamma-6)+2)\right)}>0, \\
v_{B}^{*}-v_{B}^{f} & =A \frac{t \gamma(n-1)\left(\beta_{1}-1\right)(\gamma(n(\gamma(2 n-11)+6)+13 \gamma-14)+4)}{\left(2 t\left(\beta_{1}-1\right)-1\right)\left(t(\gamma(2 n-3)+2)\left(\beta_{1}-1\right) \beta_{3}^{2}-2\left(\beta_{2}-1\right)(\gamma(n(\gamma(n-5)+3)+5 \gamma-6)+2)\right)}>0, \text { and } \\
v_{B}^{f}-v_{B}^{c s r} & =A \frac{t \gamma^{2}(n-1)^{2}\left(\beta_{1}-1\right)}{\left(2 t\left(\beta_{1}-1\right)-1\right)\left(t\left(\beta_{1}-1\right) \beta_{3}^{2}+2(\gamma-1)\left(\beta_{2}-1\right)\right)}>0 .
\end{aligned}
$$

Proposition B1 verifies that the ranking of CSR levels across competitive agreements is unaffected by whether firms select prices or quantities in Stage 2. The business stealing effect is the driving force behind Proposition B1, just like it was behind Proposition 1 when firms set quantities in Stage 2 of the game. The intuition is also identical, and discussed in Section 4.1 of the main text.

As a CSR agreement does not adjust conditional prices, and by Proposition B1 reduces CSR levels compared to the benchmark, consumer welfare always decreases with a CSR agreement. Comparing conditional prices (46) and (47) shows that a full agreement increases conditional prices compared to the benchmark. By Proposition B1, a full agreement reduces CSR levels so that consumer welfare is reduced on two accounts compared to the benchmark. As a result, the ranking of consumer welfare obtained in the main text is also valid when firms set prices instead of quantities. Denote quantity when firms set prices by subscript B.

Proposition B2. $C S\left(q_{B}^{*}\right)>C S\left(q_{B}^{c s r}\right)>C S\left(q_{B}^{f}\right)$.

Proof. In competitive regime $r$, consumer surplus (14) can be written as $C S\left(q^{r}\right)=$ $\frac{n}{2}(\gamma(n-1)+1)\left(q^{r}\right)^{2}$ as both quantities and CSR levels are symmetric. Therefore, the ranking of consumer surpluses is equivalent to that of quantities. The ranking follows from

$q_{B}^{*}-q_{B}^{c s r}=A \frac{2 t \gamma(n-1)\left(\beta_{2}-1\right)^{2} \beta_{3}}{\left(t\left(\beta_{1}-1\right) \beta_{3}^{2}+2(\gamma-1)\left(\beta_{2}-1\right)\right)\left(t(\gamma(2 n-3)+2)\left(\beta_{1}-1\right) \beta_{3}^{2}-2\left(\beta_{2}-1\right)(\gamma(n(\gamma(n-5)+3)+5 \gamma-6)+2)\right)}>0$,

and

$$
q_{B}^{c s r}-q_{B}^{f}=A \frac{t \gamma(n-1)\left(t\left(\beta_{1}-1\right) \beta_{3}-\gamma(n-2)-1\right)}{\left(t\left(\beta_{1}-1\right) \beta_{3}^{2}+2(\gamma-1)\left(\beta_{2}-1\right)\right)\left(2 t\left(\beta_{1}-1\right)-1\right)}>0 .
$$


Compared to the non-cooperative benchmark, a price agreement increases conditional prices in Stage 2 and increases CSR levels in Stage 1. Which of these two forces dominates is a priori unclear, and Proposition 8 shows that a production agreement in a duopoly can increase consumer welfare if firms set quantities in Stage 2, investing is very cheap, and goods are sufficiently similar. This result does not generalize to price competition in Stage 2, where a price agreement will always decrease consumer welfare compared to the benchmark.

Proposition B3. $C S\left(q_{B}^{*}\right)>C S\left(q_{B}^{p}\right)$.

Proof. The ranking follows from

$$
q_{B}^{*}-q_{B}^{p}=A \frac{t \gamma(n-1)\left(2 t(\gamma-1)(\gamma(2 n-3)+2)\left(\beta_{1}-1\right) \beta_{3}+\left(\beta_{2}-1\right)(n(\gamma(2 n-9)+6)+7 \gamma-10)\right)}{\left(4 t(\gamma-1)\left(\beta_{1}-1\right)+\beta_{3}\right)\left(t(\gamma(2 n-3)+2)\left(\beta_{1}-1\right) \beta_{3}^{2}-2\left(\beta_{2}-1\right)(\gamma(n(\gamma(n-5)+3)+5 \gamma-6)+2)\right.}>0 .
$$

The reason why a price agreement in which firms jointly select conditional prices can never benefit consumers is primarily that the non-cooperative benchmark produces more consumer surplus when firms select prices in Stage 2 than when firms select quantities in Stage 2. Since prices are strategic complements and quantities are strategic substitutes, price setting generates a more competitive benchmark outcome with more output than quantity setting. As a price agreement reduces quantities and increases CSR compared to the benchmark, also when firms set prices, total welfare could increase if out-of-market externalities such as those given in equation (17) are taken into account.

\section{Alternative consumer preferences}

In this appendix, we show that our consumer welfare results are robust to altering the preference structure to allow for a direct effect of CSR on consumer welfare. When firms jointly select CSR levels, our consumer welfare results are generally valid as long as consumer welfare depends positively on both output and CSR levels. This is because both a CSR agreement and a full agreement decrease output and CSR efforts compared to the non-cooperative benchmark. A production agreement always increases CSR levels compared to the non-cooperative benchmark and decreases conditional quantities. Therefore, the net effect of these two opposing forces on consumer surplus depends on the demand structure and underlying preferences that are assumed.

In our baseline quasi-linear quadratic utility model, CSR levels only indirectly influence consumer welfare through the effect of CSR levels on quantities. To shed light on the robustness of our consumer welfare comparison between a production agreement and the non-cooperative benchmark, we revisit this comparison in the context of Salop's (1979) model of product differentiation. In this model, consumer welfare is directly and positively influenced by CSR levels. The results are in line with those 
obtained in the main text: a (partial) production agreement always increases CSR levels compared to the non-cooperative benchmark, but only increases consumer welfare when goods are very similar, and investing is very cheap.

As in our baseline model, these results are mainly driven by business stealing incentives. Firms can capture a larger market share by investing in CSR in Stage 1. Given that a production agreement results in higher conditional prices in Stage 2, capturing additional consumers is more profitable in a production agreement than in the non-cooperative benchmark. When investing is cheap, and products are similar, this business stealing incentive becomes so strong in a production agreement that the positive direct effect of increased CSR levels on consumer welfare can more than compensate for the reduction in conditional prices.

Assume that all firms, and a unit mass of consumers, are equidistantly located on a circle with circumference $L>0$. Firms play a two-stage game. In Stage 1, firm $i$ sets CSR level $v_{i}$ at cost $\frac{t v_{i}^{2}}{2}$. In Stage 2, each firm $i$ selects price $p_{i}$. The consumer located at $x$ buys one unit of the good from the firm $i$ that maximizes her indirect utility

$$
V_{i}=\alpha+v_{i}-\tau\left|l_{i}-x\right|-p_{i}
$$

where $\tau>0$ is the unit transportation cost of the consumer, $l_{i}$ is the location of firm $i$ and $\alpha>0$ is a utility parameter. ${ }^{44}$ The quasi-linear utility function of the representative consumer given in equation (1) results in direct effects of CSR changes on consumer welfare being exactly offset by price changes. In contrast, in the indirect utility function given in equation (52) the direct effects of CSR levels and prices are what determine consumer welfare.

The location of the consumer indifferent between consuming firm $i$ 's product, or the product of its neighbour firm $j$, is

$$
\hat{x}_{i j}=\frac{\left(v_{i}-v_{j}\right)-\left(p_{i}-p_{j}\right)}{2 \tau}+\frac{L}{6} .
$$

The profit of each firm $i$ then depends on the prices and CSR levels of its two neighbours $j$ and $k$

$$
\pi_{i}=\left(p_{i}-c\right)\left(\hat{x}_{i j}+\hat{x}_{i k}\right)-\frac{t v_{i}^{2}}{2} .
$$

We analyze the case of three firms for tractability reasons. In Stage 2 of the noncooperative benchmark each firm $i$ selects $p_{i}$ to maximize profit (54), resulting in conditional price $p_{i}^{*}\left(v_{i}, v_{j}, v_{k}\right)$. In Stage 1 of the non-cooperative benchmark each firm $i$ selects $v_{i}$ to maximize $\pi_{i}\left(p_{i}^{*}\left(v_{i}, v_{j}, v_{k}\right), p_{j}^{*}\left(v_{i}, v_{j}, v_{k}\right), p_{k}^{*}\left(v_{i}, v_{j}, v_{k}\right), v_{i}, v_{j}, v_{k}\right)$. Denote the resulting price and CSR level as $p_{S}^{*}$ and $v_{S}^{*}$, respectively. Focus on a partial production agreement where two firms, without loss of generality firm 1 and firm 2, form a production agreement, and firm 3 does not participate in the agreement. In Stage 2 of a production agreement, firms 1 and 2 select $p_{1}$ and $p_{2}$ to maximize $\pi_{1}+\pi_{2}$, while firm 3

\footnotetext{
${ }^{44}$ The standard assumption that each consumer buys one unit implies that $\alpha$ must be sufficiently large such that utility (52) is positive for all consumers.
} 
selects $p_{3}$ to maximize $\pi_{3}$, resulting in conditional prices $p_{1}^{c}\left(v_{1}, v_{2}, v_{3}\right), p_{2}^{c}\left(v_{1}, v_{2}, v_{3}\right)$, and $p_{3}^{* *}\left(v_{1}, v_{2}, v_{3}\right)$. In Stage 1 of a production agreement, each firm $i$ selects $v_{i}$ to maximize $\pi_{i}\left(p_{1}^{c}\left(v_{1}, v_{2}, v_{3}\right), p_{2}^{c}\left(v_{1}, v_{2}, v_{3}\right), p_{3}^{* *}\left(v_{1}, v_{2}, v_{3}\right), v_{1}, v_{2}, v_{3}\right)$.

Denote the resulting price and CSR level of the two firms in the production agreement as $p_{S}^{p}$ and $v_{S}^{p}$, respectively. CSR levels of insiders and firms in the non-cooperative benchmark compare as follows (denoted by subscript $S$ ).

Proposition $\mathrm{C} 1 v_{S}^{p}>v_{S}^{*}$.

Proof. The Nash-equilibrium conditional price of firm $i$ in the non-cooperative benchmark is

$$
p_{i}^{*}=c+\frac{5 L \tau+6 v_{i}-3 \sum_{i \neq j}^{n} v_{j}}{15},
$$

The conditional price of firm 1 in a production agreement is

$$
p_{1}^{c}=c+\frac{\left(20 L \tau+15 v_{1}-3 v_{2}-12 v_{3}\right)}{36},
$$

and the conditional price of firm 2 by symmetry results when subscripts 1 and 2 are exchanged in equation (56). The conditional price of firm 3, not participating in the production agreement, is

$$
p_{3}^{* *}=c+\frac{\left(8 L \tau+6 v_{3}-3 \sum_{i \neq 3}^{n} v_{i}\right)}{18} .
$$

The Nash-equilibrium CSR level in the non-cooperative benchmark is

$$
v_{S}^{*}=\frac{4 L}{15 t} .
$$

The CSR level of a production agreement insider is

$$
v_{S}^{p}=\frac{2 L(5 t \tau-2)}{3 t(9 t \tau-4)} .
$$

In all proofs in this appendix, we consider parameter values such that an interior solution is guaranteed and the second-order conditions are satisfied: $\alpha$ large enough so that all consumers buy, and $t \tau>\frac{1}{2}$. The ranking follows from

$$
v_{S}^{p}-v_{S}^{*}=\frac{2 L(7 t \tau-2)}{15 t(9 t \tau-4)}>0 .
$$

Proposition $\mathrm{C} 1$ is in line with the baseline model: firms in a production agreement always increase CSR levels compared to the non-cooperative benchmark. By increasing conditional prices in the Stage 2, firms in a production agreement increase the incentive to invest as servicing an additional consumer is more profitable. Prices of insiders and firms in the non-cooperative benchmark compare as follows. 
Proposition $\mathrm{C} 2 p_{S}^{p}>p_{S}^{*}$

Proof. Substituting $v_{S}^{*}$ into equation (55) gives

$$
p_{S}^{*}=k+\frac{L \tau}{3} .
$$

Substituting $v_{S}^{p}$ and the Nash-equilibrium CSR level of firm 3 in a production agreement into equation (56) gives

$$
p_{S}^{p}=k+\frac{L \tau(5 t \tau-2)}{9 t \tau-4} .
$$

The ranking follows from

$$
p_{S}^{p}-p_{S}^{*}=\frac{2 L \tau(3 t \tau-1)}{3(9 t \tau-4)}>0
$$

Proposition C2 states that firms in a production agreement always increase prices compared to the non-cooperative benchmark. Like in the baseline model, we see that a production agreement increases consumer welfare by increasing CSR levels, but decreases consumer welfare by increasing prices. The next two propositions investigate the net effect on consumer welfare of a production agreement. First, note from equation (52) that the net effect of $v_{i}$ and $p_{i}$ on a consumer who purchases from firm $i$ is $v_{i}-p_{i}$. This net effect on utility compares as follows across production agreement insiders and firms in the non-cooperative benchmark.

Proposition C3 $v_{S}^{*}-p_{S}^{*}>v_{S}^{p}-p_{S}^{p}$ unless $\tau<\frac{1}{15}(6+\sqrt{6})$ and $t<\frac{1}{5} \sqrt{\frac{2}{3 \tau^{2}}}+\frac{2}{5 \tau}$.

Proof. Constructing $\left(v_{S}^{*}-p_{S}^{*}\right)-\left(v_{S}^{p}-p_{S}^{p}\right)$ from equations (58) to (61) gives

$$
\left(v_{S}^{*}-p_{S}^{*}\right)-\left(v_{S}^{p}-p_{S}^{p}\right)=\frac{2 L(3 t \tau(5 t \tau-4)+2)}{15 t(9 t \tau-4)},
$$

which is greater than 0 unless $\tau<\frac{1}{15}(6+\sqrt{6})$ and $t<\frac{1}{5} \sqrt{\frac{2}{3 \tau^{2}}}+\frac{2}{5 \tau}$.

Proposition C3 states that the net utility due to CSR levels and prices offered by an insider in a production agreement is less than the net utility offered by a firm in the non-cooperative benchmark, unless products are very similar in the horizontal sense $(\tau$ is small) and investing is cheap ( $t$ is small). As in the baseline model, when goods are similar and investing is cheap, the business stealing incentives are very large, so that firms in a production agreement invest heavily in CSR. Proposition C3 only investigates the situation for consumers who purchase from either firm 1 or 2 in both competitive regimes. However, the increased conditional prices of the firms in a production agreement cause the market share of firm 3 to increase compared to the non-cooperative benchmark. Therefore, the next proposition compares total consumer surplus across the two competitive regimes. 
Proposition C4 $C S_{S}^{*}>C S_{S}^{p}$, unless $\tau<\frac{8}{15}$ and $t<\frac{8}{15 \tau}$.

Proof. Ignoring travel costs, each consumer in the non-cooperative benchmark has utility $\alpha-v_{S}^{*}-p_{S}^{*}$, while in a production agreement consumers of firm 1 or 2 have utility $\alpha+v_{S}^{p}-p_{S}^{p}$, and consumers of firm 3 have utility $\alpha+v_{S}^{* *}-p_{S}^{* *}$. In the noncooperative benchmark, the indifferent consumers are located halfway between adjacent firms leading to the lowest possible total travel cost: $\frac{\tau L^{2}}{12}$. With a production agreement, the indifferent consumers between firm 3 and a firm in the agreement are located $\frac{L(3 t \tau-1)}{3(9 t \tau-4)}$ from the firms 1 and 2, while the indifferent consumer between firms 1 and 2 is located halfway between them, leading to total travel cost: $\frac{L^{2} \tau(3 t \tau(87 t \tau-80)+56)}{36(4-9 t \tau)^{2}}$. Summing the difference in utility net of travel costs for all consumers across the two regimes, and adding the difference in total travel cost, gives the difference in consumer surplus

$$
C S_{S}^{p}-C S_{S}^{*}=L^{2} \frac{(8-15 t \tau)(t \tau(87 t \tau-64)+12)}{90 r(4-9 t \tau)^{2}},
$$

which is positive if $\tau<\frac{8}{15}$ and $t<\frac{8}{15 \tau}$, and negative otherwise.

Proposition C4 shows that a production agreement leads to a reduction in consumer welfare in the vast majority of all cases. The results presented in Proposition C3 and Proposition $\mathrm{C} 4$ are in line with our results in the baseline model. Although a production agreement will always increase CSR levels compared to the non-cooperative benchmark, consumer welfare typically decreases, unless goods are very similar and investing is very cheap.

\section{Partial agreements with fringe competition}

In this appendix, we show that the results from our baseline model extend to partial agreements that consist of $m$ out of the $n$ firms, with the remaining $n-m$ firms forming a competitive fringe $(m<n)$. Residual competition reduces the possibilities for firms to benefit from an agreement. This causes all outcomes to lie in between the non-cooperative outcome and the outcome with a market-wide agreement. Therefore, partial agreements on CSR reduce CSR and output compared to the benchmark, but by less than market-wide agreements directly on CSR. Likewise, partial agreements on production increase CSR and reduce conditional quantities compared to the benchmark, but by less than market-wide production agreements. A two-firm production agreement in markets of up to five firms can increase its output compared to the noncooperative benchmark if investing is very cheap and goods are very similar. However, in that case, the firms in the production agreement make less profit than they would in the non-cooperative benchmark. No profitable agreement exists that simultaneously increases consumer welfare and CSR compared to the benchmark.

Without loss of generality, let $i=1, \ldots, m$ be the firms participating in the agreement, so $i=m+1, \ldots, n$ are the firms remaining in competition. We refer to members 
of the agreement as insiders and firms in the competitive fringe as outsiders. Firms play the two-stage game described in the main text, serving demand (2) at marginal production costs $c$ and CSR investment $\operatorname{costs} \frac{t v_{i}^{2}}{2}$. Let $v_{P}^{r}$ denote the CSR level of a member of a partial agreement in competitive regime $r \in\{c s r, p, f\}$. CSR levels of agreement insiders and firms in the non-cooperative benchmark compare as follows. ${ }^{45}$

Result D1. $v_{P}^{p}>v^{*}>\left\{v_{P}^{f}, v_{P}^{c s r}\right\}$.

Result D1 states that a partial production agreement is the only partial agreement that increases CSR levels compared to the non-cooperative benchmark. ${ }^{46}$ The first-order condition for firm $i$, who is an insider in a partial CSR agreement, is

$$
\sum_{i \neq j}^{n} \frac{\partial \pi_{i}}{\partial q_{j}} \frac{\partial q_{j}^{*}}{\partial v_{i}}+\frac{\partial \pi_{i}}{\partial v_{i}}+\sum_{i \neq j}^{m}\left(\sum_{i \neq j \neq k}^{n} \frac{\partial \pi_{j}}{\partial q_{k}} \frac{\partial q_{k}^{*}}{\partial v_{i}}+\frac{\partial \pi_{j}}{\partial q_{i}} \frac{\partial q_{i}^{*}}{\partial v_{i}}\right)=0 .
$$

Comparing (62) to (7) shows that each insider in a partial CSR agreement only considers the negative externality of its CSR level on $m-1$, instead of $n-1$, other firms' profit. As $m$ goes to zero, the non-cooperative outcome is approached. As $m$ goes to $n$, CSR levels converge to those of a market-wide CSR agreement. Therefore, CSR levels are always lower in a partial CSR agreement than in the non-cooperative benchmark, and the extent to which they differ is increasing in the size of the agreement: $v^{*}>v_{P}^{c s r}>v^{c s r}$.

Denote the Nash-equilibrium conditional quantities set by insiders in a partial production agreement or a partial full agreement by $q^{\text {in }}(\mathbf{v})$, and the conditional quantities set by outsiders by $q^{\text {out }}(\mathbf{v}) .{ }^{47}$ The first-order condition for a firm $i$, who is an insider in a partial production agreement, is

$$
\sum_{i \neq j}^{m} \frac{\partial \pi_{i}}{\partial q_{j}} \frac{\partial q_{j}^{i n}}{\partial v_{i}}+\sum_{k=m+1}^{n} \frac{\partial \pi_{i}}{\partial q_{k}} \frac{\partial q_{k}^{\text {out }}}{\partial v_{i}}+\frac{\partial \pi_{i}}{\partial v_{i}}+\frac{\partial \pi_{i}}{\partial q_{i}} \frac{\partial q_{i}^{i n}}{\partial v_{i}}=0
$$

\footnotetext{
${ }^{45} \mathrm{CSR}$ levels for the general $m$-of- $n$ setup are extremely lengthy and therefore omitted here. Comparing outcomes across different competitive regimes for all $n$ and $m$ is computationally infeasible. In this section we therefore report results for $3 \leq n \leq 10$ and all $2 \leq m \leq n-1$. Note that these are not simulations: for each $n$ - $m$ combination, results hold for all parameter values of $A, \gamma$, and $t$. As the expressions of quantities and CSR levels are too elaborate to present, we label our comparisons "Results" instead of "Propositions", and omit the proofs. CSR levels that solve the general game and Mathematica syntax for all the results in this section are available upon request. See Treuren and Schinkel (2018) for a more elaborate discussion of partial agreements, including quantities and CSR levels of outsiders and results for $n>10$. Allowing for $n>10$, as in Treuren and Schinkel (2018), does not affect the results presented in this appendix.

${ }^{46}$ The curly brackets in Result D1 indicate that the ordering of $v_{P}^{f}$ and $v_{P}^{c s r}$ can vary. See Treuren and Schinkel (2018) for a detailed discussion.

${ }^{47} q_{i}=q^{i n}(\mathbf{v})$ and $q_{i}=q^{\text {out }}(\mathbf{v})$ solve $\max _{q_{i}} \sum_{k=1}^{m} \pi_{k}\left(\mathbf{q}, v_{k}\right)$ for $i=1, \ldots, m$, and $\max _{q_{i}} \pi_{i}\left(\mathbf{q}, v_{i}\right)$ for $i=m+1, \ldots, n$.
} 
Comparing equation (63) to equation (8) shows that the only difference between the first-order conditions of a partial and market-wide production agreement is that the conditional quantities in a partial production agreement differ from those in a marketwide production agreement. Because $\left|\frac{\partial q_{i}^{i n}}{\partial v_{i}}\right|,\left|\frac{\partial q_{j}^{i n}}{\partial v_{i}}\right|,\left|\frac{\partial q_{j}^{\text {out }}}{\partial v_{i}}\right|$ are lowest when $m$ is small, incentives to invest for insiders in a partial production agreement increase with the size of the agreement. When $m=n, q^{i n}(\mathbf{v})=q^{c}(\mathbf{v})$, and equation (63) reduces to equation (8). For all $n$ and $m$, insiders increase their CSR levels compared to the non-cooperative benchmark because $\frac{\partial \pi_{i}}{\partial q_{i}}>0: v^{p}>v_{P}^{p}>v^{*}$.

The first-order condition for firm $i$, who is an insider in a partial full agreement, is

$$
\frac{\partial \pi_{i}}{\partial v_{i}}+\sum_{j=1}^{m} \sum_{k=m+1}^{n} \frac{\partial \pi_{j}}{\partial q_{k}} \frac{\partial q_{k}^{\text {out }}}{\partial v_{i}}=0
$$

Comparing (64) to (9) shows that an insider in a partial full agreement has an additional incentive to invest in CSR compared to a market-wide full agreement. For each insider $i$ and outsider $j$ we have $\frac{\partial \pi_{i}}{\partial q_{j}}<0$ and $\frac{\partial q_{j}^{\text {out }}}{\partial v_{i}}<0$, which shows that investing in CSR increases profit for all insiders by reducing the quantity of outsiders. This effect is larger the smaller is $m$. As $m$ increases from 0 to $n$ incentives to invest in CSR decrease as the first-order condition for an insider converges from the non-cooperative first-order condition (6) to the market-wide full agreement first-order condition (9): $v^{*}>v_{P}^{f c}>v^{p}$. $^{48}$

Consumer surplus is a function of the quantities of all insiders and outsiders in a partial agreement, as shown by equation (14). As we are interested in the behavior of insiders, and as in consumer surplus is a function of quantities, we focus on the quantities of insiders as a measure of the agreement's contribution to consumer surplus. Denote by $q_{P}^{r}$ the quantity of an agreement insider in competitive regime $r \in\{c s r, p, f\}$. Comparing quantities across the benchmark, a CSR agreement, and a full agreement, we obtain the following result.

Result D2. $q^{*}>q_{P}^{c s r}>q_{P}^{f}$.

Result D2 states that allowing insiders to coordinate their CSR levels decreases the quantity they produce compared to the non-cooperative benchmark, regardless of the size of the competitive fringe. A CSR agreement produces the non-cooperative quantity conditional on CSR levels in Stage 2. By Result D1 and the discussion following it, we know that a partial CSR agreement decreases CSR levels compared to the noncooperative benchmark, and that CSR levels are reduced by more the more firms take part in the agreement. It follows that $q^{*}>q_{P}^{c s r}>q^{c s r}$.

\footnotetext{
${ }^{48}$ If $\left|\sum_{i \neq j}^{n} \frac{\partial \pi_{i}}{\partial q_{j}} \frac{\partial q_{j}^{*}}{\partial v_{i}}\right|+\sum_{i \neq j}^{m} \sum_{i \neq j \neq l}^{n}\left|\frac{\partial \pi_{j}}{\partial q_{l}} \frac{\partial q_{l}^{*}}{\partial v_{i}}\right|-\sum_{i \neq j}^{m}\left|\frac{\partial \pi_{j}}{\partial q_{i}} \frac{\partial q_{i}^{*}}{\partial v_{i}}\right|>\left|\sum_{j=1}^{m} \sum_{k=m+1}^{n} \frac{\partial \pi_{j}}{\partial q_{k}} \frac{\partial q_{k}^{\text {out }}}{\partial v_{i}}\right|$ then $v_{P}^{c s r}>$ $v_{P}^{f}$. This happens when consumers view products as close substitutes ( $\gamma$ is close to 1 ).
} 
Insiders in a partial full agreement reduce quantities both by reducing conditional quantities in Stage 2, and by reducing CSR levels in Stage 1. The first-order condition of an insider in Stage 2 of a partial full agreement or a partial production agreement is

$$
\frac{\partial \pi_{i}}{\partial q_{i}}+\sum_{i \neq j}^{m} \frac{\partial \pi_{j}}{\partial q_{i}}=0
$$

which shows that an insider's incentive to reduce its conditional quantity compared to the non-cooperative benchmark is increasing in agreement size $m$, as $\frac{\partial \pi_{j}}{\partial q_{i}}<0$. For insiders in a partial full agreement, by Result D1 we know that the incentive to decrease CSR levels compared to the non-cooperative benchmark also increases in $m$. It follows that $q^{*}>q_{P}^{f}>q^{f} \cdot{ }^{49}$ Quantities of partial production agreement insiders and firms in the non-cooperative benchmark compare as follows.

Result D3. $q^{*}>q_{P}^{p}$ unless $m=2, n \in\{3,4,5\}$, and $t<T_{P}(\gamma, n)$, in which case $\pi^{*}>\pi_{i n}^{p c} 50$

Result D3 states that insiders in a partial production agreement will decrease their output compared to the non-cooperative benchmark unless the production agreement consists of two firms, there are no more than three outsiders, investing is very cheap ( $t$ is low), and goods are very similar ( $\gamma$ is high). When $q_{P}^{p}>q^{*}$, insiders in a partial production agreement make less profit than firms in the non-cooperative benchmark. Recall that a production agreement increases CSR levels, but reduces conditional quantities, compared to the non-cooperative benchmark. In a market-wide production agreement, the reduction of conditional quantities is increasing in $n$, as the benchmark quantity is increasing in $n$. In a partial production agreement, the reduction of conditional quantities is still increasing in $n$, but equation (65) shows that the reduction of conditional quantities is also increasing in $m$, such that the reduction of conditional quantities is smallest if both $m$ and $n$ are small. In that case, insiders can increase quantities compared to the non-cooperative benchmark if investing is very cheap and products are very similar. Just as in the market-wide agreement case, these parameters result in the firms engaging in a CSR arms race that leaves firms worse off compared to the non-cooperative benchmark. ${ }^{51}$

\footnotetext{
${ }^{49}$ Let $\Delta v_{P}^{c s r}=v_{P}^{c s r}-v^{*}, \Delta v_{P}^{f}=v_{P}^{f}-v^{*}$, and $\Delta q^{i n}=q^{i n}\left(v^{*}\right)-q^{*}\left(v^{*}\right)$. As $\left|\frac{\partial q^{i n}}{\partial v} \Delta v_{P}^{f}+\Delta q^{i n}\right|>$ $\left|\frac{\partial q^{*}}{\partial v} \Delta v_{P}^{c s r}\right|$, we have $q_{P}^{c s r}>q_{P}^{f}$.

${ }^{50} T_{P}(\gamma, 3)=\frac{4+5 \gamma-2 \gamma^{2}-\gamma^{3}}{4\left(2+2 \gamma-3 \gamma^{2}-2 \gamma^{3}+\gamma^{4}\right)}+\frac{1}{4} \sqrt{\frac{-2 \gamma^{2}-15 \gamma^{3}-16 \gamma^{4}+2 \gamma^{5}-6 \gamma^{6}+\gamma^{7}}{(\gamma-2)\left(\gamma^{2}-1\right)^{2}\left(\gamma^{2}-2 \gamma-2\right)^{2}}}, \quad T_{P}(\gamma, 4)=$ $\frac{-32-64 \gamma+16 \gamma^{2}+30 \gamma^{3}-7 \gamma^{4}-3 \gamma^{5}}{4\left(4+4 \gamma-5 \gamma^{2}+\gamma^{3}\right)\left(-4-4 \gamma+5 \gamma^{2}+3 \gamma^{3}\right)}+\frac{1}{4} \sqrt{\frac{256 \gamma^{2}+1536 \gamma^{3}+2112 \gamma^{4}-416 \gamma^{5}-444 \gamma^{6}+588 \gamma^{7}+61 \gamma^{8}-102 \gamma^{9}+9 \gamma^{10}}{\left(4+4 \gamma-5 \gamma^{2}+\gamma^{3}\right)^{2}\left(-4-4 \gamma+5 \gamma^{2}+3 \gamma^{3}\right)^{2}}}, \quad$ and $T_{P}(\gamma, 5)=\frac{-8-26 \gamma-9 \gamma^{2}+16 \gamma^{3}+\gamma^{4}-4 \gamma^{5}}{4\left(4+6 \gamma-6 \gamma^{2}+\gamma^{3}\right)\left(-1-2 \gamma+\gamma^{2}+2 \gamma^{3}\right)}+\frac{1}{4} \sqrt{\frac{36 \gamma+252 \gamma^{3}+505 \gamma^{4}+132 \gamma^{5}-234 \gamma^{6}+136 \gamma^{7}+129 \gamma^{8}-72 \gamma^{9}+16 \gamma^{10}}{\left(4+6 \gamma-6 \gamma^{2}+\gamma^{3}\right)^{2}\left(-1-2 \gamma+\gamma^{2}+2 \gamma^{3}\right)^{2}}}$.

${ }^{51}$ It is noteworthy that for $n>3$ total quantity will always decrease as outsiders actually reduce quantity in Nash-equilibrium compared to the non-cooperative benchmark. See Treuren and Schinkel (2018) for details.
} 